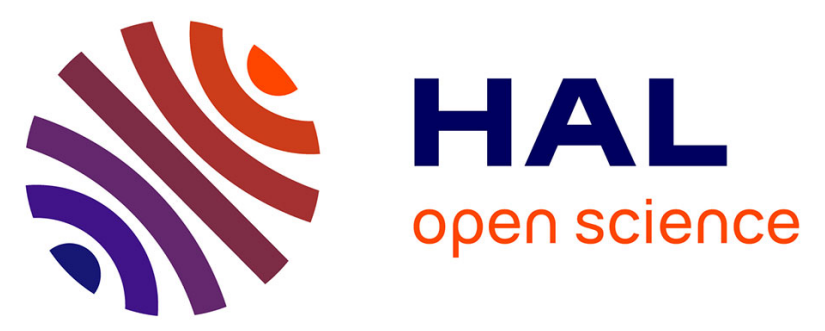

\title{
Influence of moisture uptake on the static, cyclic and dynamic behaviour of unidirectional flax fibre-reinforced epoxy laminates
}

Michaël Berges, Romain Léger, Vincent Placet, Véronique Person, Stéphane Corn, Xavier Gabrion, Jérôme Rousseau, Emmanuel Ramasso, Patrick Ienny,

Stéphane Fontaine

\section{To cite this version:}

Michaël Berges, Romain Léger, Vincent Placet, Véronique Person, Stéphane Corn, et al.. Influence of moisture uptake on the static, cyclic and dynamic behaviour of unidirectional flax fibre-reinforced epoxy laminates. Composites Part A: Applied Science and Manufacturing, 2016, 88, pp.165-177. 10.1016/j.compositesa.2016.05.029 . hal-01480243

\section{HAL Id: hal-01480243 https://hal.science/hal-01480243}

Submitted on 1 Mar 2017

HAL is a multi-disciplinary open access archive for the deposit and dissemination of scientific research documents, whether they are published or not. The documents may come from teaching and research institutions in France or abroad, or from public or private research centers.
L'archive ouverte pluridisciplinaire HAL, est destinée au dépôt et à la diffusion de documents scientifiques de niveau recherche, publiés ou non, émanant des établissements d'enseignement et de recherche français ou étrangers, des laboratoires publics ou privés. 


\title{
Influence of moisture uptake on the static, cyclic and dynamic behaviour of unidirectional flax fibre-reinforced epoxy laminates
}

\author{
Michaël Berges ${ }^{1}$, Romain Léger ${ }^{1}$, Vincent Placet $^{2 *}$, Véronique Person ${ }^{3}$, Stéphane Corn ${ }^{1}$ Xavier Gabrion², \\ Jérôme Rousseau ${ }^{3}$, Emmanuel Ramasso $^{2}$, Patrick Ienny ${ }^{1}$, Stéphane Fontaine ${ }^{3}$
}

${ }^{1}$ C2MA, Ecole des mines d'Alès, F-30319 Alès, France.

${ }^{2}$ FEMTO-ST UMR6174, Univ. Bourgogne Franche-Comté, F-25000 Besançon.

${ }^{3}$ DRIVE EA1859, Univ. Bourgogne Franche-Comté, F-58000 Nevers, France.

* Corresponding author: Email: vincent.placet@univ-fcomte.fr

tel: +33 (0)3 81666055 - fax: +33(0)3 81666700

\begin{abstract}
This papers aims to characterize the influence of moisture uptake on the mechanical behaviour of unidirectional flax fibre-reinforced epoxy laminates. Monotonic and cyclic tensile tests and free vibration characterization are carried out. Results show that UD flax-epoxy composites, when exposed to hygrothermal conditioning at $70^{\circ} \mathrm{C}$ and $85 \%$ RH, exhibit a diffusion kinetic which follows a one dimensional Fickian behaviour. The mass uptake at equilibrium is approximately $3.3 \%$ and the diffusion coefficient $6.510^{-6} \mathrm{~m}^{2} \mathrm{~s}^{-1}$. Water vapour sorption is shown to induce a significant change in the shape of the tensile stress-strain curve, a decrease in the dynamic elastic modulus of about $20 \%$ and a $50 \%$ increase in the damping ratio. Contrary to all expectations, water saturation does not degrade the monotonic tensile strength of such a flax-epoxy composites and leads to an increase in the fatigue strength for a high number of cycles.
\end{abstract}

Keywords: A. Polymer-Matrix Composites, A. Natural fibres, B. Mechanical properties, C. Moisture 


\section{NOMENCLATURE}

\section{Mechanics}

$\sigma_{\mathrm{L}}:$ tensile strength in fibre direction

$\sigma_{\mathrm{T}}$ : tensile strength in transverse direction

$\varepsilon_{\mathrm{L}}$ : tensile strain at failure in fibre direction

$\varepsilon_{\mathrm{T}}$ : tensile strain at failure in transverse direction

$v_{\mathrm{LT}}, v_{\mathrm{TL}}$ : Poisson's ratios (determined using linear

regression between $0.01 \%$ and $0.15 \%$ axial strain)

$\mathrm{E}_{L}^{m 1}$ : axial apparent modulus determined under

monotonic tensile loading using linear regression

between $0.01 \%$ and $0.15 \%$ strain

$\mathrm{E}_{L}^{m 2}$ : axial apparent modulus determined under monotonic tensile loading using linear regression between $0.4 \%$ and strain at failure

$\mathrm{E}_{T}^{m}$ : transverse apparent modulus determined under monotonic tensile loading using linear regression between $0.01 \%$ and $0.15 \%$ strain

$E_{L}^{*}$ : axial dynamic modulus determined from the peak-to-peak amplitudes of strain and stress during fatigue tests

$\mathrm{E}_{L}^{d}$ : axial dynamic elastic modulus determined using free vibration analysis

$\xi$ : damping ratio determined using free vibration analysis

\section{Physics}

D: diffusion coefficient

$\mathrm{M}_{\mathrm{m}}$ : water mass uptake at equilibrium

$M$ : specimen mass

$h$ : thickness

A: area

$\rho_{\mathrm{c}}$ : composite density

$\rho_{f}$ : fibre density

$\rho_{\mathrm{m}}$ : matrix density

$\mathrm{W}_{\mathrm{f}}$ : fibre weight fraction

$\mathrm{V}_{\mathrm{f}}$ : fibre volume fraction

$\mathrm{V}_{\mathrm{m}}$ : matrix volume fraction

$\mathrm{V}_{\mathrm{v}}$ : void volume fraction 


\section{INTRODUCTION}

Due to the concerns about environment, sustainability issues, new rules and regulations, biobased materials have raised growing interest from numerous industries [1]. The considerable attraction of the worldwide research community and the rapid growth in innovation is warranted to the unique intrinsic properties such as biodegradability, availability, environmental friendliness, and physico-mechanical properties of this group of materials. [2-4].

Thanks to outstanding research accomplishments and recent development efforts, plant fibres reinforced composites have been developed. They are usually dedicated to non-structural applications, i.e. where high loading capacity is not required. These applications take place in automotive, aerospace, packaging and building industries.

Fibre with high mechanical properties can be extracted from plants, such as flax, hemp, sisal for example. They are good candidates to be used as composite reinforcements for lightweight structural applications. Up-to-date critical reviews of literature [1,5-10] show that several technological and scientific barriers still remain to be knocked down in order to obtain fully optimised plant fibre composites (PFCs) for structural applications. One of the main question concerns the long-term durability of such composites. Indeed, for some intended applications, PFCs will be heavily exposed to moisture, various temperatures and UV radiations. These environmental loadings can strongly affect their mechanical properties and therefore play a critical role in the service life of PFCs.

Up to now, the influence of temperature on the mechanical properties of plant fibres and PFC has been mainly characterized with a view to improving the composites manufacturing processes, in particular for thermoplastic matrices [11-13].

Moisture absorption is a phenomenon affecting most of polymer composites when placed in humid atmosphere or immersed in water. Water uptake can lead to a change in the physical, chemical, mechanical and dimensional properties of the matrix (plasticization, hydrolysis, swelling as a function of its affinity with water). It can also degrade fibre-matrix interface. This results in a decrease in the stress transfer efficiency and thus in the mechanical properties of the composite material. Contrary to glass or carbon fibres, plant fibres have a high affinity with water. This property gives composite materials a high water uptake capacity. Water vapour or liquid water can thus be easily absorbed by PFCs through fibres. Into the wall of plant fibres, water is absorbed 
through hydrogen bonds. It induces breaks into the secondary interactions between cellulose macromolecules, it also causes swelling and modifies the mechanical properties of the fibres [14-17]. It is therefore of paramount importance to characterize moisture absorption and its influence on the long-term behaviour of PFCs.

In the literature, several studies have been focused on this topic for different types of PFCs [18]. Le Duigou et al. [19-21] studied the influence of sea water immersion and ageing on flax PLA biocomposites. They showed a linear relationship between water uptake and loss of mechanical properties [20]. They also pointed out, using in situ nano-indentation, that the fibre wall rigidity decreases when immersion time increases [21].

For hemp fibre reinforced polyester composites, water absorption was found to follow a Fickian behaviour at room temperature and a non-Fickian one at high temperatures [22]. A non-Fickian behaviour was also observed for hemp-polypropylene composite [23]. For those composite materials, authors also showed that the time required to reach water saturation decreases significantly when the immersion temperature increases. In addition, the tensile and flexural properties of these hemp-polyester composites were found to decrease as the percentage of moisture uptake increases [22].

In the case of flax-epoxy composites, several studies pointed out that the evolution of water absorption follows a Fickian law. Moreover, kinetics of water uptake is clearly influenced by the temperature level [24, 25]. Scida et al. [24] showed that water vapour sorption induces a significant reduction of the Young's modulus but only a slight decrease in strength. They also noticed a change in the shape of the tensile curve. Munoz et al. [25] showed that water uptake increases when fibre weight content increases. Moreover, they noticed that, while the tensile modulus decreases with the absorption of water, the tensile strength of wet specimens is higher than that of dry samples.

This review on PFCs also shows that the influence of moisture on durability has been mainly studied from a quasi-static behaviour perspective. Only few papers deal with fatigue [26] or vibration [27, 28] behaviours. These lacks need to be filled in order that plant fibres can be considered as viable reinforcement for composite materials in structural applications.

Fatigue of flax-epoxy composites has been recently studied under ambient conditions [29-36]. Results show that these composite materials exhibit good fatigue performance. The latter are considered comparable to those measured on composites reinforced with glass fibres. This points out the potential of flax epoxy composites to be implemented in load-bearing applications. Bensadoun et al. [35] underlined that the fibre architecture has a 
strong effect on the fatigue behaviour of these composite materials. Hence, best fatigue characteristics are reached when using fibres with architectures that lead to the highest static strengths and moduli. Despite these recent works on fatigue, the influence of moisture absorption and environmental loading has not been yet considered.

Thus, the purpose of this paper is to investigate and quantify the influence of water vapour absorption on the mechanical properties of flax fibres reinforced epoxy composites, using quasi static, fatigue and vibration tests. This work was conducted as part of the scientific collaboration between three French laboratories (DRIVE, FEMTO-ST and C2MA), which are members of a research consortium called BioComp. This consortium groups several partners with expertise in the field of mechanics of fibre and reinforcements, manufacturing and characterization of plant reinforcements, polymers and composites, biochemistry as well as chemistry of interfaces.

\section{MATERIAL AND METHODS}

\section{$\underline{\text { Composite material }}$}

Composite biobased-materials have been fabricated from prepregs flax fibres and epoxy resin. FlaxPreg UD 150 was supplied by Lineo company (France). The flax fabric has an areal weight of $154 \mathrm{~g} / \mathrm{m}^{2}$. It contains 95\% of warp yarns and 5\% of weft yarns in weight. The epoxy resin is an Epoxy Huntsman LY 5150. The fibre fraction is approximately $50 \%$ in weight before curing.

\section{Composite fabrication}

Six plates (400 mm x $400 \mathrm{~mm} \times 2.2 \mathrm{~mm}$ ) were fabricated in DRIVE lab using a thermo-compression process under specific pressure and temperature cycle (see Fig.1). These plates consist in 10 elementary unidirectional plies. Each plate has been characterized in terms of porosity and fibre contents according to the ASTM D 317199 standard. In order to evaluate the fibre, matrix and voids volume fractions, samples of $30 \mathrm{~mm} \times 25 \mathrm{~mm}$ were cut from the plates. The mass $M$, thickness $h$ and area $A$ of each specimen were measured.

The density of the composite $\rho_{c}$ and the fibre weight fraction in specimen $W_{f}$ were first determined using the following equations: 
$\rho_{c}=\frac{M}{h \cdot A} \quad W_{f}=\frac{A_{r} \cdot n \cdot A}{M}$

where $\mathrm{n}$ is the number of plies of the tested laminate and $A_{r}$ is the mass of one ply per unit area. Then, the fibre volume fraction $V_{f}$, matrix volume fraction $V_{m}$ and void volume fraction $V_{v}$ were calculated using Eq. 2.

$$
V_{f}=W_{f} \cdot \frac{\rho_{c}}{\rho_{f}} \quad V_{m}=\left(1-W_{f}\right) \cdot \frac{\rho_{c}}{\rho_{f}} \quad V_{v}=1-V_{f}-V_{m}
$$

where $\rho_{f}$ and $\rho_{m}$ represent respectively the fibre and matrix densities.

A scanning electron microscope (Hitachi S-3000N) has also been used to observe the cross-section areas of the produced materials. Images have been recorded under partial vacuum with back-scattered electrons. A specific attention was dedicated to the study and the distribution of the voids (Fig. 2). On such an image, the warp yarns (white areas, which represent approximately $95 \%$ of the reinforcement structure), the epoxy matrix (grey areas) and the voids (black areas) can be easily identified. The presence of weft yarns, which represent approximately $5 \%$ of the reinforcement structure, is also easily observed. A summary of the plate properties is presented in table 1.

\section{Sample preparation}

Rectangular specimens ( $250 \mathrm{~mm}$ in length and $25 \mathrm{~mm}$ in width) were sawn with a high-speed diamond cutting machine, in the fibre direction $\left(0^{\circ}\right)$ for one part, and perpendicularly to the fibre direction $\left(90^{\circ}\right)$ for the other part. After surface preparation (sanding then cleaning with acetone), aluminium tabs (50 $\mathrm{mm}$ in length, $25 \mathrm{~mm}$ in width and $3 \mathrm{~mm}$ in thickness) have been bonded to the test specimens dedicated to quasi-static and fatigue tests. DRIVE used a two-component adhesive (Huntsman Araldite 2015) and performed a heating of the assemblies at $40{ }^{\circ} \mathrm{C}$ for 2 hours with a slight pressure applied to the tabs. FEMTO-ST and C2MA used a Loctite Super Glue 3 adhesive to bond specimen and aluminium tabs.

Samples used for monotonic tests were also prepared for strain measurement. DRIVE equipped samples with 2 strain gages (Kyowa KFG-10-120-C1-11) in axial and transverse direction. Samples were speckled at C2MA in order to estimate the in plane strain tensor by digital image correlation [37]. 


\section{Hygrothermal conditioning}

After fabrication, samples were stored in a climatic chamber at $21^{\circ} \mathrm{C}$ and $50 \% \mathrm{RH}$ before mechanical testing. This hygroscopic state was named "DRY". Samples were also aged in a climatic chamber at $70^{\circ} \mathrm{C}$ and $85 \% \mathrm{RH}$ for more than 2 weeks. During this period, relative weight uptake, dimensions, dynamic tensile modulus and damping were monitored. A Mettler-Toledo AT200 balance was used for weight monitoring (precision of $0.001 \mathrm{~g}$ ), a calliper with a precision of $10^{-2} \mathrm{~mm}$ was used to evaluate the swelling and a specific "home" set-up (presented in a following section) was employed to carry out the dynamic properties of aged specimens. At the end of the two-week monitoring period, an equilibrium state named WVS (Water Vapour Saturated state) has been achieved.

\section{Mechanical testing}

\section{Monotonic tensile tests (MTT)}

The tensile properties were determined by the three partners (DRIVE, FEMTO-ST and C2MA) using their own testing procedures. Results will be later discussed in terms of robustness and repeatability. Relevance of existing norms for composite materials will be discussed. Actually, the ISO 527-4 standard recommends to measure the elastic modulus by linearization of strain between 0.05 and $0.25 \%$. However, it is known that plant fibre composites present a strongly non-linear behaviour at low strain. These recommendations should therefore be questioned [38-40]. When displaying the derivative of stress as a function of strain, the tangent modulus can be plotted (Fig. 3). On this figure, tangent modulus is not constant and presents a strong variation for these strains

levels. As a consequence, we have chosen to evaluate this modulus in a similar and reduced strain domain (0.01$0.15 \%)$ to compare results. Strain measurements techniques in each lab are precisely described below.

\section{MTT1 (DRIVE):}

Uniaxial tensile measurements were carried out in both direction $0^{\circ}$ and $90^{\circ}$ on a tensile testing machine (MTS Criterion C45) equipped with a load cell of $100 \mathrm{kN}$.

The speed of the tests was $2 \mathrm{~mm} / \mathrm{min}$. Ten specimens (five by tested direction) were tested until failure. Young's modulus and Poisson's ratios were calculated between two levels of longitudinal deformation: $\varepsilon=0,01 \%$ and $\varepsilon=0,15 \%$. 
MTT2 (C2MA):

Young modulus and ultimate tensile stress and strain were determined by uniaxial tensile tests on a MTS testing machine (model Criterion C45.105) equipped with a $100 \mathrm{kN}$ load cell. Samples were loaded at a crosshead speed of $1 \mathrm{~mm} / \mathrm{min}$. Modulus was evaluated in the strain interval of $0.01-0.15 \%$ using linear regression.

For each set of samples (DRY and WVS) oriented at $0^{\circ}, 3$ specimens were tested, while for samples oriented at $90^{\circ}, 5$ specimens were tested.

MTT3 (FEMTO-ST):

A hydraulic testing machine (Instron 8501) equipped with a load sensor with a measurement range of $100 \mathrm{kN}$ was used to carry out tensile tests in the fibre direction. A $5 \mathrm{kN}$ load sensor was used for the transverse direction. The axial and transverse strains were measured using clip-on extensometers, with respective gauge length of $45 \mathrm{~mm}$ and $25 \mathrm{~mm}$. The tensile stress was computed by dividing the applied load by the initial cross-section of the specimen. Samples were subjected to a displacement control; with a $2 \mathrm{~mm} \cdot \mathrm{min}^{-1}$ moving crosshead speed. Tests were carried out up to failure. For the determination of the Young's modulus, considering that the materials do not have a strong linear relationship between stress and strain, even at very low stresses, a tangent method was used. The tangent modulus was expressed as a function of the axial strain. Two apparent moduli were also determined using linear regression respectively between $0.01 \%$ and $0.15 \%$ of strain $\left(\mathrm{E}_{L}^{m 1}\right)$ and between $0.4 \%$ and strain at failure $\left(\mathrm{E}_{L}^{m 2}\right)$.

For each set of samples, 3 to 6 specimens were tested and results are presented in terms of average and standard deviation values.

\section{Tensile-tensile fatigue tests}

The tensile-tensile fatigue tests were performed under a triangular waveform loading at a frequency of $5 \mathrm{~Hz}$, using a load amplitude control mode, and a ratio between minimum and maximum stress $(\mathrm{R})$ of 0.1 . The experimental configuration (loading machine, specimen shape and preparation) was similar to monotonic tensile tests (MTT3, FEMTO tests). Fatigue tests were performed in the fibre direction for DRY and WVS specimens. Four levels of maximum stress were applied. The levels were $80 \%, 65 \%, 50 \%$ and $40 \%$ of the quasistatic tensile failure stress (at $2 \mathrm{~mm} \cdot \mathrm{min}^{-1}$ ) for the DRY specimens and approximately $75 \%, 60 \%, 55 \%$ and 45 $\%$ for the VWS specimens. At least three replicates were tested at each stress level. Tests were stopped at failure. 
Tests were carried out under controlled hygrothermal conditions $\left(\mathrm{T}=21{ }^{\circ} \mathrm{C} \pm 3{ }^{\circ} \mathrm{C}, \mathrm{RH}=50 \% \pm 5 \%\right)$. For WVS specimens, it was necessary to keep the water-saturated state during fatigue loading. Thus, the specimens were covered after the hygrothermal treatment with a flexible coating film. This one was elaborated from an aqueous mixture of iron oxide-filled acrylic resin. The mass of each specimen was measured after hygrothermal treatment and also before and after fatigue loading. The mass variation was checked to be negligible and the water-saturation state has been assumed to be constant during tests.

Peak-to-peak and average amplitudes of load and strain sensors were recorded for each cycle. A complete cycle was also recorded as a function of a logarithmic progression whose common difference depends on the stress level and thus fatigue test duration.

\section{Free vibration tests}

The viscoelastic parameters (elastic modulus and loss factor) of composite samples were determined using vibration analysis. This technique, which aims at studying the dynamic behaviour of a structure thanks to its natural vibration modes [41], is non-destructive. It is thus well suited for monitoring materials during water sorption or ageing.

For this study, the set-up simulates free boundary conditions by supporting the sample with soft suspensions. The sample, a $250 \mathrm{~mm} \times 25 \mathrm{~mm}$ beam, is excited in free vibration by an impulse hammer (Kistler 9722A2000). Its response is measured by an accelerometer (Kistler 8778A500). An additional steel mass $\left(\mathrm{m}_{0}=\mathrm{m}_{\mathrm{L}}=86 \mathrm{~g}\right)$ was clamped at each end of the beam in order to bring down the natural frequency $f_{l}$ of its first "tensioncompression" mode into a measurable frequency range $(100-9000 \mathrm{~Hz})$.

The resonant frequencies of the sample are given by the series of peaks in the frequency response function (Fig.

4). The software MODAN®, developed by the FEMTO-ST (Franche-Comté University, Besançon, France), was used to extract eigen frequencies and damping ratios from the frequency response function (by using a curve fitting technique).

Then, derived from the equation of the elastodynamic equilibrium of the tension-compression mode, the expression of the axial (i.e. longitudinal) elastic modulus $\mathrm{E}_{L}^{d}$ is given by expression (3): 
$E_{L}^{d}=\frac{\rho L^{2} f_{1}^{2}}{\left(\frac{\beta_{1}}{\pi}\right)^{2}}$

with $\beta_{1}$ being the lowest positive root of equation (4):

$\beta_{1} \cdot \tan \beta_{1}=\frac{m}{M_{t}}$

where $M_{t}$ is the total added mass ( $172 \mathrm{~g}$ ), $L$ and $m$ being respectively the length and the mass of the part of the sample located between these two clamped masses, and $\rho$ its density.

The damping ratio $(\xi)$ of the first tenson-compression mode is extracted from the impulse response in the vicinity of the corresponding resonance peak thanks to MODAN®.

Before hygrothermal conditioning 10 specimens were tested for each plate, while the moduli of 6 specimens were followed throughout water vapour until saturation.

\section{$\underline{\text { Optical and SEM observations }}$}

Pre-failure and post-failure microscopic observations of the cross-section of some DRY and WVS specimens were performed to inspect the defects and damage progress in the composite when submitted to fatigue loading. These clichés allow to characterize the influence of water vapour sorption. Small coupons were cut in the tensile specimens with a diamond blade and embedded in a PMMA resin. The embedded coupons were grinded and polished. The observations were done using an optical microscope (Nikon Eclipse LV150) and an environmental SEM (FEI Quanta 450W).

\section{$\underline{\text { Acoustic emission (AE) }}$}

Some of the monotonic and fatigue tests were instrumented with acoustic emission measurements. A twochannel data acquisition system (Euro Physical Acoustics, MISTRAS Group) was used. This system comprises miniature piezoelectric sensors $(\mu-80)$ with a resonance frequency ranging from $250-325 \mathrm{kHz}$, preamplifiers with a gain of 20 or $40 \mathrm{~dB}$, a $20-1000 \mathrm{kHz}$ filter, a PCI card with a $5 \mathrm{MHz}$ sampling rate. The sensors were coupled onto the specimen faces using silicone grease. They were placed at the gauge extremities with a distance 
of $130 \mathrm{~mm}$ between their centres. System calibration was performed after installing the transducers on the specimen and before each test, using a pencil lead break procedure.

AE signals treatment and data processing and interpretation were done using home-made methodology and software. This methodology was developed in FEMTO-ST laboratory during the last years to reliably analyze and interpret AE data when collected in complex experimental configurations, such as during fatigue tests. This methodology relies on two steps.

- The first step includes: (i) a real time AE data streaming, (ii) AE hits' determination and separation and (iii) conventional AE features extraction (MARSE energy, amplitude, average frequency, root mean square, average signal level, count-to-peak, reverberation frequency, initiation frequency, signal strength, absolute energy, partial power in [0 250] kHz, [250 500] kHz, [500 750] kHz and [750 1000] $\mathrm{kHz}$, centroid frequency, peak frequency and weighted peak frequency). This method is widely described in [42]. Denoising was performed using discrete-wavelet transform. Hits' determination and separation was achieved using the conventional amplitude threshold-based technique. A threshold of $35 \mathrm{~dB}$ was used. The timing parameters: PDT (Peak Definition Time) $=60 \mu \mathrm{sec}$; HDT (Hit Definition Time $)=120 \mu \mathrm{sec}$ and HLT (Hit Lock Time) $=300 \mu \mathrm{sec}$ were identified by means of preliminary calibration measurements.

- The second step is focused on the data clustering, which involves the classification of the AE hits into groups (clusters) representing the AE sources. The proposed approach is a robust-to-parameterization and unsupervised method based on clustering fusion. It is based on the idea that, using unsupervised pattern recognition techniques, several parametrizations may be suitable for a given dataset but it is difficult to precisely find an optimal one. Therefore, the clustering fusion makes possible the determination of a robust result with uncertainty quantification.

In this second step, all combinations of subsets of 4 features from the previous list (leading 2380 cases) are considered separately for clustering. The algorithm of Gustafson-Kessel is used [43]. A preselection of the most relevant partitions (among the 2380 ones) is automatically conducted using an entropy-based measure calculated on the clusters' proportions. This method is described in a previous paper [43]. For those multifarious subsets, the number of clusters in the Gustafson-Kessel algorithm was varied from 2 to 8 . To select the best number of clusters, a second criterion based on 
both the mutual information and a set of boostrapped ensembles computed on clusters' proportions was applied. This method was initially suggested in [44, 45] and adapted for AE data processing in [43]. This method thus allows to make use of multifarious parameterizations (subsets of features, number of clusters and other parameters used in clustering) and to ensure robust results particularly for large datasets. Finally, the set of partitions can be used to estimate confidence bounds on the final partition which is of particular interest for AE data processing under uncertainty.

\section{RESULTS AND DISCUSSION}

\section{$\underline{\text { Water Vapour absorption behaviour }}$}

Fig. 5 displays the water uptake of samples in the humid environment described before. The diffusion kinetics follows a one dimensional Fickian behaviour (solid lines in Figure 5) as presented by Scida et al. [24]. After 6 days, the average mass uptake reached at equilibrium $\mathrm{M}_{\mathrm{m}}$ is approximately $3.3 \pm 0.2 \%$. The coefficient of diffusion $\mathrm{D}$ is estimated at $6.47 \times 10^{-6} \pm 0.14 \times 10^{-6} \mathrm{~m}^{2} \cdot \mathrm{s}^{-1}$. It is interesting to notice the difference in kinetics observed for P5 specimen. This specimen shows a lower mass uptake at equilibrium. This phenomenon can be explained by its lower void ratio $(6.3 \%)$ in comparison to other specimens from P2 and P6 (with a void ratio of respectively 7.2 and $8.1 \%$ - see Tab. 1$)$.

Globally, the void contents of the plates manufactured during this study are comprised between 4.9 and $8.6 \%$. This result is in agreement with the work of Meredith et al. [46] which highlighted a high void content with Lineo Flaxpregs (up to $10 \%$ ). The authors suggested a lack of resin in their prepreg. The same issue is likely to be encountered in our case. Furthermore, we can suppose that air bubbles were trapped between the layers during the lay-up. Moreover, during the process, two other phenomena shall occur: (i) the yarns represent obstacles and limit the evacuation of air during the lay-up process (ii) the resin mainly flows into the yarns because of lower internal capillary pressure, as pointed out by Shah et al. in [47].

\section{Influence of moisture absorption on the mechanical behaviour}

\section{Monotonic tensile behaviour}

Fig. 6 shows the typical stress-strain curves under tensile loading of UD composite laminates in the fibre direction and perpendicularly to the fibre direction for DRY specimens. All results obtained by the three partners 
are given in Table 2. The mean values of tensile moduli (approximately $30 \mathrm{GPa}$ in the fibre direction and 4.7 $\mathrm{GPa}$ in the transverse direction), tensile strength (approximately $320 \mathrm{MPa}$ in the fibre direction and $30 \mathrm{MPa}$ in the transverse direction) and strain at failure (approximately $1.5 \%$ in the fibre direction and $1 \%$ in the transverse direction) are in good agreement with data of literature collected on the same type of flax-epoxy UD $[29,39]$. In the longitudinal direction, a really good agreement is also observed between the mean values and coefficients of variation $(\mathrm{CoV})$ determined by the three different laboratories involved in this study. The difference in mean values is generally comprised between 5 and $10 \%$ between labs for these tensile properties. Readers have to keep in mind that the experimental devices and some of the techniques (strain measurements, tabs gluing...) were different between the different labs. The loading rate was also two times slower in MTT2 when compared to MTT1 and MTT3. Despite these differences in the experimental implementation of the tests, the obtained values are quite similar. This reflects the good homogeneity of material properties obtained with this material and manufacturing process. The $\mathrm{CoV}$ is lower than $6 \%$ for the strength, $10 \%$ for the rigidity for each lab.

Fig.7 displays the same curves for samples extracted in the fibre direction before (DRY) and after water vapour saturation (WVS). For DRY specimens, the tensile curve is strongly non-linear. Its shape is identical that the one depicted by other authors for the same type of UD material [24, 31, 39, 47, 48]. Poilâne et al. [39] showed that this non-linear behaviour can be attributed to time-dependent mechanisms and well represented by a viscoelastoplastic model. The microstructural origin of such non-linearity remains an open question in the scientific community, and could be attributed to reorganization mechanisms at the scale of yarns and of fibre wall.

Fig. 7 also shows that water absorption induces a change in the stress-strain curve of samples extracted in the fibre direction. An increase of failure strains, a decrease of the Young's modulus as well as a slight increase of the Poisson's ratio are observed (Tab.2). These evolutions can be attributed to the plasticization of both matrix and fibres by water molecules. WVS specimens exhibit slightly superior tensile strengths to DRY specimens. Munoz and Garcia-Manrique [25] also observed a higher tensile strength of flax-epoxy composites after immersion. They attributed this behaviour to the swelling of flax fibres in the composite material (as a result of 
water absorption). This phenomenon was assumed to induce a stronger interfacial bonding between the fibres and the matrix. Water sorption also increases the macromolecules mobility [24].

On Fig. 8, another interesting feature can be observed and concerns the tangent modulus. For DRY specimens, this modulus is decreasing towards a finite value $\left(\mathrm{E}_{L}^{m 2}\right)$. Concerning WVS specimens, this modulus is slightly increasing at large longitudinal strains. Such a phenomenon has already been mentioned by other authors [49, 50]. This could be attributed to the alignment of cellulosic microfibrils or to the crystallisation of amorphous cellulose in the wall of flax fibres.

\section{Tensile-tensile fatigue behaviour}

S-N curves for tensile-tensile fatigue tests on DRY and WVS specimens are presented in Fig. 9. For each studied load level, and particularly for WVS specimens, there is a slight dispersion in the maximum tensile stress. This is due to the variation in cross-section of the specimens. Results show that both sets of specimens (DRY and WVS) present a gradual decline in fatigue strength with increasing number of fatigue cycles. For a given loading level, dispersion in fatigue life duration is observed. The order of magnitude of this dispersion is in agreement with data collected on flax-epoxy laminates $[29,30,32]$. The fatigue strength as a function of number of cycles can be fitted by the Wöhler law. The fatigue strength for a high number of cycles (1 million) is approximatively $140 \mathrm{MPa}$ for DRY specimens. This value represents approximately $42 \%$ of the monotonic tensile strength. It is in agreement with the works El Sawi et al. [29]. They found a fatigue strength (for 6 million cycles) in the range of 45 to $50 \%$ of ultimate tensile stress for the same type of unidirectional flax-epoxy laminates.

Moreover, both mean strain $\varepsilon_{\text {mean }}$ and dynamic modulus $E_{L}^{*}$ have been calculated at each fatigue cycle. The evolution of these values is plotted in Figs. 10a and 10b.

Under the lowest stress levels (40,50 and $65 \%$ of ultimate tensile stress), the mean strain is strongly increasing until a life fraction comprised between 0.05 and 0.1 . Following this increasing, the mean strain reaches a plateau. Just before failure, a sudden increasing is observed. Under highest stress level (80\% of ultimate tensile stress, see Fig. 10a), the slope of the second stage is higher than for the lower stress level up to 0.4 of life fraction. The mean strain tends to be stabilized at this level after this point.

This increase in mean strain as a function of fatigue cycles could be attributed to a time-dependent behaviour. Indeed, in plant-based composite, both matrix and fibres can develop viscoelastic behaviour. Recently, it has 
been shown that bast fibres are characterized by a significant time-dependent behaviour when submitted to tensile testing $[51,52]$. In addition to this behaviour, irreversible phenomena such as damage or plastic effects can occur. These dependences were mentioned by El Sawi et al. [29]. They showed a positive correlation between the mean strain evolution and cracks ratios in a laminate.

Moreover, Fig. 10b clearly shows a raise in stiffness when the number of cycles increases. The initial dynamic modulus is approximately $34 \mathrm{GPa}$ for the tested specimen. For the higher stress levels $(65 \%$ and $80 \%$ of ultimate tensile stress), a slight decrease in dynamic modulus can be observed during the first fatigue cycles (up to $33 \mathrm{GPa}$ ). During the second phase of fatigue cycling, a clear increase in stiffness is observed. It overpasses the initial stiffness. Under the lower stress levels (40\% and $50 \%$ of ultimate tensile stress), a sharp increase is observed in the early part of the fatigue test. A plateau is then reached until the failure of the specimen. The stiffness increase for these stress levels is of approximately 7 to $8.5 \%$. These values are in agreement with those reported by Liang et al. [32] and El Sawi et al. [29].

This stiffness increase under cyclic loading can be attributed to various phenomena, at different scales, such as flax fibre hardening or fibre re-orientation. Plant fibres have been observed to become stiffer when they are submitted to cyclic tensile loading $[14,50,53-55]$. This was attributed both to cellulose microfibrils reorientation $[14,50,56]$ and stress-induced crystallization of amorphous cellulose in the fibre wall. This phenomena has also been observed and recently highlighted by Shah [36] and Bensadoun et al. [35] in the case of flax-epoxy composites.

So, the tensile fatigue behaviour of unidirectional flax-epoxy laminates seems to result from the combination of antagonistic mechanisms. Hence, since creep and damage induce an increase in mean strain and a decrease in apparent stiffness, fibres hardening, due to microstructural mechanisms, seem to induce a slight increase of the laminates stiffness.

Results (Figs 9, 10c, 10d) show that the fatigue strength is significantly influenced by water sorption. Regarding WVS specimens, the initial dynamic modulus is $22 \mathrm{GPa}$, against $33 \mathrm{GPa}$ for DRY specimens. Contrary to all expectations, the fatigue strength for a high number of cycles is higher for WVS specimens than for DRY ones. In the case of WVS specimens, the fatigue strength reaches $155 \mathrm{MPa}$ (47\% of the monotonic tensile strength), 
see Fig. 9. Moreover, the mean strain is higher when testing DRY specimens (Fig. 10c). This phenomenon is assumed to be due to the plasticization of the laminate. The evolution of the mean strain (Fig. 10c) and dynamic modulus (Fig. 10d) is similar to the one observed for DRY specimens. The stiffness respectively increases by $22 \%$ and $32 \%$ under maximum stresses levels of $180 \mathrm{MPa}(55 \%$ of ultimate tensile stress) and $155 \mathrm{MPa}(45 \%$ of ultimate tensile stress). This result clearly shows that the laminate hardening phenomenon is activated by water sorption. An activation of such a hardening phenomenon by water sorption has already been observed under cyclic loading of plant fibres [14].

Fig. 11 proposes typical stress-strain hysteresis loops of various fatigue cycles $\left(\mathrm{n}^{\circ} 1,125,3125\right.$ and 78125$)$ of DRY (maximum dynamic stress $=50 \%$ of monotonic tensile strength) and WVS specimens (maximum dynamic stress $=55 \%$ of monotonic tensile strength). Hysteresis loops provide a valuable insight into the material stiffness and internal friction and their evolution during fatigue [57]. The loop area is indeed proportional to the dissipated energy. Results exhibit hysteresis loops with diminishing area as the number of cycles increases, for both DRY and WVS specimens, as well as an increase of the dynamic modulus. This decrease in loop area could be explained by a decrease in damage activity when the number of fatigue cycles is increasing. This hypothesis was proposed by Towo and Ansell for sisal fibre reinforced composites [57]. Fig. 12 shows the evolution of the AE activity (i.e. the cumulated number of AE hits) as a function of the fatigue cycles for the different stress levels. Results point out that the damage activity is generally high during the first stage of cycling, except for the fatigue stress level equal to $50 \%$ of the monotonic tensile strength. For this stress level, the damage activity is almost constant during fatigue test. This result confirms that damage activity could partly explain the dissipated energy (and the significant area of the hysteresis loop) that is observed during the first stage of fatigue tests. But, it cannot be the only explanation since, for $50 \%$ loading level, the damage activity is constant (Fig. 12c) and the loop area still decreases when fatigue cycles is increasing (Fig. 11a). Thus, this decrease in loop area could also comes from a decrease in the damping capacity of flax fibres, resulting from microstructural rearrangement within the fibre wall, such as cellulose microfibrils reorientation. Such a reorientation of the cellulose microfibrils could explain both the hardening phenomenon (increase in rigidity in the fibre direction) and the decrease in damping capacity. The viscoelasticity is indeed higher in the transverse direction of cellulose MFs than in the axial one. It was shown previously for plant fibres that the increase in stiffness under cyclic tensile loading is also accompanied with a decrease in damping capacity [54]. 
On Fig.11, it can also be observed that the dissipated energy is higher for water saturated specimens. It can be explained by the increase in damping capacity provided by water sorption of both matrix and flax fibres.

\section{Fatigue damage}

The fatigue damage in such flax-epoxy laminates has been studied by El Sawi et al. [29]. They reported microcracks inside the bundles of fibres, between the elementary fibres. These cracks induce, at the early stage of lifetime, delamination between adjacent fibres. With increasing number of cycles, at $2 / 3$ of fatigue life, they showed that such cracks propagate inside the bundle and through the matrix. Failures at the interface between bundles and matrix were also observed at this stage.

In the present work, we observed the same damage kinetics in the DRY specimens submitted to fatigue loading (Fig. 13 a ,b, c and d). More surprisingly, for the WVS specimens, cracks were not observed inside the bundles of fibres but in the matrix and more precisely at the interface between the yarns of fibres and the matrix (Fig. $13 \mathrm{e}, \mathrm{f}$ and $\mathrm{g}$ ). This difference could be explained by the swelling of individual fibres inside the bundles, induced by water sorption in the fibre wall, when the composite are exposed to humidity. This sorption-induced swelling of fibres could result in a stronger strength at the interface between individual fibres inside the bundles and thus explain the higher fatigue strength of WVS specimens when compared to DRY specimens. Then, the tensile strength of WVS laminates would be more driven by the strength at the interface between the yarns and the matrix.

These images and observations are useful to inspect the defects and damage progress in the composite when submitted to fatigue loading. However, results have to be considered with great care considering the potential influence of sample preparation (including composite cutting, coupons embedding, grinding and polishing) on the damage state. The mode of visualisation is also important and may involve interaction between the probe and the composite, and more particularly the plant fibres. SEM observations can, for example, induce deformation or shrinkage, and as a consequence damage, due to the use of low vacuum conditions, and produce significant surface modifications due to electron beam damage.

Thus, damage during fatigue tests has also been assessed using acoustic emission. Data collected on WVS specimens are not relevant for comparison purpose, since the presence of a cover layer highly distorts and attenuates the waves that are recorded at the surface of the composite materials. For this reason, only the results collected on the DRY specimens are considered in this study. 
The clustering fusion methodology was applied on the fatigue datasets recorded at the different level of stress. Results are presented on Fig. 14 and Tab. 3 for a specimen tested at $65 \%$ of the monotonic tensile strength. Fig. 14 shows the activity within each cluster. The solid lines represent the best result of clustering fusion. The colored envelopes describe the uncertainty resulting from clustering parametrization. Tab. 3 provides the clusters labels, their thresholds, amplitude range and cumulated acoustic energy. The threshold represents the number of cycles before the first appearance of a given cluster, i.e. of an acoustic source.

The number of clusters was automatically determined to 5 using the proposed methodology. One of the main difficulty with unsupervised pattern recognition techniques is to label clusters, i.e. to assign each cluster to the corresponding acoustic source. This was partially done using in situ or/and post mortem optical observations and prior knowledge of acoustic signature of plant fibres and PFCs damage [58, 59].

Cluster 1 , which first starts, is characterized by relatively low amplitude $(50 \mathrm{~dB})$ and energy $(1 \%$ of the total AE energy), despite comprising $89 \%$ of the AE hits. This cluster was assigned to external sources, including electromagnetic and mechanical noises (rubbing and friction) which are mainly generated by the actuating systems, electronic equipment and the surrounding environment. The second cluster is made of higher amplitudes $(87 \mathrm{~dB})$ and represents about $10 \%$ of the released acoustic energy. It begins early (before cycle $n^{\circ} 150$ ). Cluster 3 and 4 started around cycles $n^{\circ} 300$ to 400 and are characterized by amplitude close to 96 and $102 \mathrm{~dB}$ while representing $80 \%$ of the total released energy. These 3 clusters are certainly related to cracks initiation and propagation in the matrix and within the bundles of fibres, fibre debonding and individual fibre breakage. However, the available results are not enough to reliably assign these clusters to their respective damage families or sub-families, and clearly deserve further investigations using 3D inspection techniques such as tomography.

The fifth source of AE hits is activated from around cycle $n^{\circ} 750$ until the end of the test. It has the highest amplitudes $(107 \mathrm{~dB})$. The energy released by this source represents $9.4 \%$ of the total AE energy with only $0.06 \%$ of the total number of $\mathrm{AE}$ hits which means that the $\mathrm{AE}$ events related to this source are highly energetic. This source may be related to the breakage of bundles of fibres or yarns. This was correlated with visual observations during fatigue tests.

Even if additional work is still needed to ensure damage assessment of PFCs under fatigue loading, these results illustrate yet the capacity of the proposed AE methodology to discriminate damage families and 
subfamilies. They also show that during the first hundred fatigue cycles, an intense damage activity is observed. It is mainly related to cracks propagation in the matrix and at the interface between individual fibres. Such dissipative mechanisms could explain partly the significant area of the hysteresis loops measured in the first stage of fatigue tests.

\section{Dynamic behaviour}

Dynamic elastic modulus $E_{L}^{*}$ and damping ratio evaluated for DRY and WVS samples are given in Table 4. Dynamic elastic moduli are greater than quasi-static moduli because of the viscoelastic character of PFC. As a comparison, values are plotted on Fig.8. An extrapolation of the quasi-static tangent modulus, measured during monotonic tests, at low strain logically tends towards the dynamic elastic modulus value. It can be underlined that in this dynamic technique, the specimen is submitted to tensile -compression loadings and that the behaviour of plant fibre composite is generally different in compression and tension [60]. After water vapour saturation, dynamic elastic modulus is decreasing by $20 \%$. However, damping ratio is increasing by $50 \%$. This increase in damping ratio provided by water sorption and measured using free vibration test is consistent with the increase in damping capacity observed on the same material under the previous tensile-tensile fatigue tests. This is assumed to be due to the plasticization of both matrix and fibres by water molecules.

\section{CONCLUSIONS}

This study focused on the consequences of water vapour sorption of unidirectional flax-epoxy laminates. Mechanical investigations concerned monotonic, fatigue and dynamic behaviours. The motivation of this work was to evaluate the durability of biobased laminates for structural applications. The goal was particularly to characterize and understand the influence of moisture absorption and weathering on the mechanical behaviour and long-term behaviour of PFCs. It is necessary to safely and reliably introduce them in the structural composite market.

Results show that, when exposed to hygrothermal conditioning at $70^{\circ} \mathrm{C}$ and $85 \% \mathrm{RH}$, the diffusion kinetics of UD flax-epoxy composites follows a one dimensional Fickian behaviour. Water vapour sorption is showed to induce a significant change in the shape of the tensile stress-strain curve, a decrease in dynamic elastic modulus 
and a large increase in damping ratio (approximately 50\%). Contrary to all expectations, water saturation does not degrade the monotonic tensile strength of such a flax-epoxy composites. Moreover, an increase in the fatigue strength is clearly observed for wet specimens. Water sorption seems to activate some hardening phenomena. This is a benefit both for the static and fatigue strength. This result is of paramount importance for biobased composites end-users. Future of this work will help to quantify the influence of time of exposure to such hygrothermal conditions (i.e. ageing) on the mechanical behaviours of PFCs. The final purpose is to understand how microstructural mechanisms help to harden such biobased laminates when they are submitted to moisture and mechanical loading.

\section{Acknowledgements}

The authors thank the Fondation de Coopération Scientifique Bourgogne Franche-Comté for its financial support through the project Bonus Qualité Recherche «Durabilité des composites biosourcés » (FCS-BFC BQR2014-19). The authors also express theirs thanks to Marina Raschetti from FEMTO-ST for the MEB support.

\section{REFERENCES}

[1] Shah D. Developing plant fibre composites for structural applications by optimising composite parameters: a critical review. Journal of Materials Science. 2013;48(18):6083-107.

[2] Thakur VK, Thakur MK. Processing and characterization of natural cellulose fibers/thermoset polymer composites. Carbohydrate Polymers. 2014;109:102-17.

[3] Thakur VK, Thakur MK, Gupta RK. Review: Raw Natural Fiber-Based Polymer Composites. International Journal of Polymer Analysis and Characterization. 2014;19(3):256-71.

[4] Pickering KL, Efendy MGA, Le TM. A review of recent developments in natural fibre composites and their mechanical performance. Composites Part A: Applied Science and Manufacturing. 2016;83:98-112. [5] Summerscales J, Dissanayake N, Virk A, Hall W. A review of bast fibres and their composites. Part 2 Composites. Composites Part A: Applied Science and Manufacturing. 2010;41(10):1336-44.

[6] Dittenber DB, GangaRao HVS. Critical review of recent publications on use of natural composites in infrastructure. Composites Part A: Applied Science and Manufacturing. 2012;43(8):1419-29.

[7] Bhowmick M, Mukhopadhyay S, Alagirusamy R. Mechanical properties of natural fibre-reinforced composites. Textile Progress. 2012;44(2):85-140.

[8] Huber T, Müssig J, Curnow O, Pang S, Bickerton S, Staiger M. A critical review of all-cellulose composites. Journal of Materials Science. 2012;47(3):1171-86 LA - English.

[9] Koronis G, Silva A, Fontul M. Green composites: A review of adequate materials for automotive applications. Composites Part B: Engineering. 2013;44(1):120-7.

[10] La Mantia FP, Morreale M. Green composites: A brief review. Composites Part A: Applied Science and Manufacturing. 2011;42(6):579-88. 
[11] Liang S, Nouri H, Lafranche E. Thermo-compression forming of flax fibre-reinforced polyamide 6 composites: influence of the fibre thermal degradation on mechanical properties. Journal of Materials Science. 2015;50(23):7660-72.

[12] Gourier C, Le Duigou A, Bourmaud A, Baley C. Mechanical analysis of elementary flax fibre tensile properties after different thermal cycles. Composites Part A: Applied Science and Manufacturing. 2014;64:159-66.

[13] Placet V, Trivaudey F, Cisse O, Gucheret-Retel V, Boubakar ML. Diameter dependence of the apparent tensile modulus of hemp fibres: A morphological, structural or ultrastructural effect? Composites Part A: Applied Science and Manufacturing. 2012;43(2):275-87.

[14] Placet V, Cisse O, Boubakar ML. Influence of environmental relative humidity on the tensile and rotational behaviour of hemp fibres. Journal of Materials Science. 2012;47(7):3435-46.

[15] Davies G, Bruce D. Effect of Environmental Relative Humidity and Damage on the Tensile Properties of Flax and Nettle Fibers. Textile Research Journal. 1998;68(9):623-62.

[16] Stamboulis A, Baillie CA, Peijs T. Effects of environmental conditions on mechanical and physical properties of flax fibers. Composites Part A: Applied Science and Manufacturing. 2001;32(8):1105-15.

[17] Symington MC, Banks WM, West OD, Pethrick RA. Tensile Testing of Cellulose Based Natural Fibers for Structural Composite Applications. Journal of Composite Materials. 2009;43(9):1083-108.

[18] Mokhothu TH, John MJ. Review on hygroscopic aging of cellulose fibres and their biocomposites. Carbohydrate Polymers. 2015;131:337-54.

[19] Le Duigou A, Davies P, Baley C. Seawater ageing of flax/poly(lactic acid) biocomposites. Polymer Degradation and Stability. 2009;94(7):1151-62.

[20] Le Duigou A, Bourmaud A, Davies P, Baley C. Long term immersion in natural seawater of Flax/PLA biocomposite. Ocean Engineering - Innovation in High Performance Sailing Yachts - INNOVSAIL.

2014;90:140-8.

[21] Le Duigou A, Bourmaud A, Baley C. In-situ evaluation of flax fibre degradation during water ageing. Industrial Crops and Products. 2015;70:204-10.

[22] Dhakal HN, Zhang ZY, Richardson MOW. Effect of water absorption on the mechanical properties of hemp fibre reinforced unsaturated polyester composites. Composites Science and Technology. 2007;67(78):1674-83.

[23] Toubal L, Cuilli Ã“re J-C, Bensalem K, Francois V, Gning P-B. Hygrothermal effect on moisture kinetics and mechanical properties of hemp/polypropylene composite: Experimental and numerical studies. Polym Compos. 2015:n/a.

[24] Scida D, Assarar M, PoilÃ $\not$ ne C, Ayad R. Influence of hygrothermal ageing on the damage mechanisms of flax-fibre reinforced epoxy composite. Composites Part B: Engineering. 2013;48(0):51-8.

[25] Munoz E, Garcia-Manrique JA. Water Absorption Behaviour and Its Effect on the Mechanical Properties of Flax Fibre Reinforced Bioepoxy Composites. International Journal of Polymer Science. 2015;ID 390275.

[26] Sodoke K, Toubal L, Laperrière L. Hygrothermal effects on fatigue behavior of natural fibers composites. 20th International Conference on Composite Materials. Copenhagen, Denmark2015.

[27] Duc F, Bourban PE, Månson JAE. The role of twist and crimp on the vibration behaviour of flax fibre composites. Composites Science and Technology. 2014;102:94-9.

[28] Le Guen M-J, Newman RH, Fernyhough A, Staiger MP. Tailoring the vibration damping behaviour of flax fibre-reinforced epoxy composite laminates via polyol additions. Composites Part A: Applied Science and Manufacturing. 2014;67:37-43.

[29] El Sawi I, Fawaz Z, Zitoune R, Bougherara H. An investigation of the damage mechanisms and fatigue life diagrams of flax fiber-reinforced polymer laminates. Journal of Materials Science. 2014;49(5):2338-46. [30] Shah DU, Schubel PJ, Clifford MJ, Licence P. Fatigue life evaluation of aligned plant fibre composites through S-N curves and constant-life diagrams. Composites Science and Technology. 2013;74(0):139-49.

[31] Liang S, Gning PB, Guillaumat L. A comparative study of fatigue behaviour of flax/epoxy and glass/epoxy composites. Composites Science and Technology. 2012;72(5):535-43.

[32] Liang S, Gning P-B, Guillaumat L. Properties evolution of flax/epoxy composites under fatigue loading. International Journal of Fatigue. 2014;63(0):36-45.

[33] Asgarinia S, Viriyasuthee C, Phillips S, Dubé M, Baets J, Van Vuure A, et al. Tension-tension fatigue behaviour of woven flax/epoxy composites. Journal of Reinforced Plastics and Composites. 2015;34(11):85767. 
[34] Ueki Y, Liholt H, Madsen B. Fatigue behavior of uni-directional flax fibre/epoxy composites. 20th International Conference on Composite Materials. Copenhagen, Denmark2015.

[35] Bensadoun F, Verpoest I, Van Vuure AW. Residual properties and damage evolution of flax-epoxy composites subjected to fatigue loading. 20th International Conference on Composite Materials2015.

[36] Shah DU. Damage in biocomposites: Stiffness evolution of aligned plant fibre composites during monotonic and cyclic fatigue loading. Composites Part A: Applied Science and Manufacturing.

[37] Christmann A, Ienny P, Quantin JC, Caro-Bretelle AS, Lopez-Cuesta JM. Mechanical behaviour at large strain of polycarbonate nanocomposites during uniaxial tensile test. Polymer. 2011;52(18):4033-44.

[38] Liang S, Gning P-B, Guillaumat L. Quasi-static behaviour and damage assessment of flax/epoxy composites. Materials \& Design. 2015;67:344-53.

[39] Poilâne C, Cherif ZE, Richard F, Vivet A, Ben Doudou B, Chen J. Polymer reinforced by flax fibres as a viscoelastoplastic material. Composite Structures. 2014;112(0):100-12.

[40] Andersons J, Modniks J, Spārniņš E. Modeling the nonlinear deformation of flax-fiber-reinforced polymer matrix laminates in active loading. Journal of Reinforced Plastics and Composites. 2015;34(3):24856.

[41] Corn S, Dupuy JS, Ienny P, Daridon L. Vibration analysis techniques for detecting filler-matrix decohesion in composites. Revue des Composites et des Matériaux Avancés. 2012;22(1):77-90.

[42] Kharrat M, Ramasso E, Placet V, Boubakar ML. A signal processing approach for enhanced Acoustic Emission data analysis in high activity systems: Application to organic matrix composites. Mechanical Systems and Signal Processing. 2016;70-71:1038-55.

[43] Ramasso E, Placet V, Boubakar ML. Unsupervised Consensus Clustering of Acoustic Emission TimeSeries for Robust Damage Sequence Estimation in Composites. IEEE Transactions on Instrumentation and Measurement. 2015;64(12):3297-307.

[44] Fred A, Jain A. Combining multiple clusterings using evidence accumulation. IEEE Transactions on Pattern Analysis and Machine Intelligence. 2005;27(6):835-50.

[45] Kuncheva LI, Bezdek JC, Duin RPW. Decision templates for multiple classifier fusion: an experimental comparison. Pattern Recognition. 2001;34(2):299-314.

[46] Meredith J, Coles SR, Powe R, Collings E, Cozien-Cazuc S, Weager B, et al. On the static and dynamic properties of flax and Cordenka epoxy composites. Composites Science and Technology. 2013;80:31-8.

[47] Shah DU, Schubel PJ, Licence P, Clifford MJ. Determining the minimum, critical and maximum fibre content for twisted yarn reinforced plant fibre composites. Composites Science and Technology.

2012;72(15):1909-17.

[48] Baets J, Plastria D, Ivens J, Verpoest I. Determination of the optimal flax fibre preparation for use in UD flax-epoxy composites. ECOCOMP, 4th International Conference on Sustainable Materials, Polymers and Composites. Birmingham, United Kingdom.2011. p. 1-21.

[49] Charlet K, Eve S, Jernot JP, Gomina M, Breard J. Tensile deformation of a flax fiber. Procedia Engineering - Mesomechanics 2009. 2009;1(1):233-6.

[50] Placet V, Cisse O, Boubakar L. Nonlinear tensile behaviour of elementary hemp fibres. Part I:

Investigation of the possible origins using repeated progressive loading with in situ microscopic observations. Composites Part A: Applied Science and Manufacturing. 2014;56:319-27.

[51] Guicheret-Retel V, Cisse O, Placet V, Beaugrand J, Pernes M, Boubakar ML. Creep behaviour of single hemp fibres. Part II: Influence of loading level, moisture content and moisture variation. Journal of Materials Science. 2015;50(5):2061-72.

[52] Cisse O, Placet V, Guicheret-Retel V, Trivaudey Fdr, Boubakar ML. Creep behaviour of single hemp fibres. Part I: viscoelastic properties and their scattering under constant climate. Journal of Materials Science. 2015;50(4):1996-2006.

[53] Baley C. Analysis of the flax fibres tensile behaviour and analysis of the tensile stiffness increase. Composites Part A: Applied Science and Manufacturing. 2002;33(7):939-48.

[54] Placet V. Characterization of the thermo-mechanical behaviour of Hemp fibres intended for the manufacturing of high performance composites. Composites Part A: Applied Science and Manufacturing. 2009;40(8):1111-8.

[55] Silva FdA, Chawla N, de Toledo Filho RD. An experimental investigation of the fatigue behavior of sisal fibers. Materials Science and Engineering: A. 2009;516(1-2):90-5. 
[56] Trivaudey Fdr, Placet V, Guicheret-Retel V, Boubakar ML. Nonlinear tensile behaviour of elementary hemp fibres. Part II: Modelling using an anisotropic viscoelastic constitutive law in a material rotating frame. Composites Part A: Applied Science and Manufacturing. 2015;68(0):346-55.

[57] Towo AN, Ansell MP. Fatigue of sisal fibre reinforced composites: Constant-life diagrams and hysteresis loop capture. Composites Science and Technology. 2008;68(3-4):915-24.

[58] de Vasconcellos DS, Touchard F, Chocinski-Arnault L. Tension-tension fatigue behaviour of woven hemp fibre reinforced epoxy composite: A multi-instrumented damage analysis. International Journal of Fatigue. 2014;59(0):159-69.

[59] De Rosa IM, Santulli C, Sarasini F. Acoustic emission for monitoring the mechanical behaviour of natural fibre composites: A literature review. Composites Part A: Applied Science and Manufacturing. 2009;40(9):1456-69.

[60] Van Vuure AW, Baets J, Wouters K, Hendrickx K. Compressive properties of natural fibre composites. Materials Letters. 2015;149:138-40.

Table 1: Plate thickness, porosity and fibre/matrix volume fractions

\begin{tabular}{|c|c|c|c|c|c|}
\hline Plates & $\begin{array}{c}\text { Thickness } \\
(\mathrm{mm})\end{array}$ & $\begin{array}{c}\text { Fibre volume } \\
\text { ratio }(\%)\end{array}$ & $\begin{array}{c}\text { Matrix volume } \\
\text { ratio }(\%)\end{array}$ & $\begin{array}{c}\text { Void volume } \\
\text { ratio }(\%)\end{array}$ & Dedicated to \\
\hline $\mathrm{P} 1$ & 2.19 & 45.0 & 46.4 & 8.6 & $\begin{array}{l}\text { Monotonic } \\
\text { (MTT3) and } \\
\text { fatigue tests } \\
\text { (DRY } \\
\text { specimens) }\end{array}$ \\
\hline $\mathrm{P} 2$ & 2.18 & 45.4 & 47.4 & 7.2 & $\begin{array}{l}\text { Fatigue tests } \\
\text { (WVS } \\
\text { specimens) }\end{array}$ \\
\hline P3 & 2.18 & 46.1 & 49 & 4.9 & $\begin{array}{c}\text { Monotonic } \\
\text { (MTT1)tests } \\
\text { (DRY } \\
\text { specimens) }\end{array}$ \\
\hline $\mathrm{P} 4$ & 2.16 & 45.6 & 47.7 & 6.7 & \multirow{3}{*}{$\begin{array}{c}\text { Monotonic } \\
\text { (MTT2) and } \\
\text { vibratory tests } \\
\text { (DRY and } \\
\text { WVS } \\
\text { specimens) }\end{array}$} \\
\hline P5 & 2.17 & 45.7 & 48.0 & 6.3 & \\
\hline P6 & 2.17 & 45.8 & 46.1 & 8.1 & \\
\hline
\end{tabular}

Table 2: Properties obtained in monotonic tensile tests (mean value \pm standard deviation)

\begin{tabular}{|c|c|c|c|c|c|c|c|c|c|c|}
\hline \multicolumn{2}{|c|}{ Specimens } & $\begin{array}{c}\sigma_{\mathrm{L}} \\
(\mathrm{MPa})\end{array}$ & $\begin{array}{c}\sigma_{\mathrm{T}} \\
(\mathrm{MPa})\end{array}$ & $\begin{array}{c}\varepsilon_{\mathrm{L}} \\
(\%)\end{array}$ & $\begin{array}{c}\varepsilon_{\mathrm{T}} \\
(\%)\end{array}$ & $\begin{array}{c}\mathrm{E}_{L}^{m 1} \\
(\mathrm{GPa})\end{array}$ & $\begin{array}{c}E_{L}^{m 2} \\
(\mathrm{GPa})\end{array}$ & $\begin{array}{c}\mathrm{E}_{T}^{m} \\
(\mathrm{GPa}) \\
\end{array}$ & $\begin{array}{c}v_{\mathrm{LT}} \\
(-) \\
\end{array}$ & $\begin{array}{l}v_{\mathrm{TL}} \\
(-) \\
\end{array}$ \\
\hline \multirow[t]{3}{*}{ DRY } & MTT1 & $\begin{array}{c}311 \\
\pm 13.9\end{array}$ & $\begin{array}{c}31.2 \\
\pm 0.84\end{array}$ & $\begin{array}{c}1.50 \\
\pm 0.12\end{array}$ & $\begin{array}{c}0.96 \\
\pm 0.08\end{array}$ & $\begin{array}{c}31.6 \\
\pm 0.96\end{array}$ & & $\begin{array}{c}4.71 \\
\pm 0.33\end{array}$ & $\begin{array}{c}0.36 \\
\pm 0.02\end{array}$ & $\begin{array}{c}0.07 \\
\pm 0.01\end{array}$ \\
\hline & MTT2 & $\begin{array}{l}319 \\
\pm 20\end{array}$ & $\begin{array}{l}30.0 \\
\pm 1.3\end{array}$ & $\begin{array}{c}1.59 \\
\pm 0.14\end{array}$ & $\begin{array}{c}0.99 \\
\pm 0.16\end{array}$ & $\begin{array}{l}30.4 \\
\pm 2.7\end{array}$ & / & $\begin{array}{c}4.69 \\
\pm 0.74\end{array}$ & $\begin{array}{c}0.34 \\
\pm 0.02\end{array}$ & / \\
\hline & MTT3 & $\begin{array}{r}327 \\
\pm 9.8 \\
\end{array}$ & $\begin{array}{l}27.7 \\
\pm 0.3 \\
\end{array}$ & $\begin{array}{c}1.45 \\
\pm 0.15 \\
\end{array}$ & $\begin{array}{c}1 \\
\pm 0.15 \\
\end{array}$ & $\begin{array}{c}32.9 \\
\pm 3.16 \\
\end{array}$ & $\begin{array}{c}19.6 \\
\pm 3.16 \\
\end{array}$ & $\begin{array}{r}4.80 \\
\pm 0.25 \\
\end{array}$ & $\begin{array}{c}0.36 \\
\pm 0.02 \\
\end{array}$ & $\begin{array}{c}0.06 \\
\pm 0.006 \\
\end{array}$ \\
\hline WVS & MTT2 & $\begin{array}{l}320 \\
\pm 20\end{array}$ & $\begin{array}{l}25.9 \\
\pm 1.5\end{array}$ & $\begin{array}{c}2.32 \\
\pm 0.14\end{array}$ & $\begin{array}{c}1.80 \\
\pm 0.21\end{array}$ & $19.6 \pm 2.0$ & l & $\begin{array}{c}3 \\
\pm 0.27\end{array}$ & $\begin{array}{c}0.37 \\
\pm 0.02\end{array}$ & l \\
\hline
\end{tabular}


Table 3 - Clusters labels and AE source thresholds for a DRY specimen tested under fatigue loading at $65 \%$ of the tensile monotonic strength. Failure was observed after 15068 cycles.

\begin{tabular}{|c|c|c|c|c|c|}
\hline $\begin{array}{l}\text { Cluster } \\
\text { number }\end{array}$ & $\begin{array}{l}\text { Number of AE } \\
\text { Hits }\end{array}$ & $\begin{array}{l}\text { AE source } \\
\text { threshold } \\
\text { (number of } \\
\text { fatigue cycles) }\end{array}$ & $\begin{array}{l}\text { Amplitude } \\
\text { (main mode +/- } \\
\text { std) }\end{array}$ & $\begin{array}{l}\text { Cumulated } \\
\text { acoustic } \\
\text { energy (in \% of } \\
\text { the total } \\
\text { cumulated } \\
\text { energy) }\end{array}$ & Interpretation \\
\hline 1 & 162910 & 1 & $50+/-7 \mathrm{~dB}$ & $0.1 \%$ & $\begin{array}{l}\text { External } \\
\text { sources } \\
\text { (mechanical } \\
\text { noises from } \\
\text { testing } \\
\text { machine...) }\end{array}$ \\
\hline 2 & 11623 & 150 & $87+/-6 \mathrm{~dB}$ & $9.9 \%$ & \multirow{4}{*}{$\begin{array}{l}\text { Sources } \\
\text { related to } \\
\text { composite } \\
\text { damage }\end{array}$} \\
\hline 3 & 4759 & 300 & $96+/-6 \mathrm{~dB}$ & $30.9 \%$ & \\
\hline 4 & 1830 & 376 & $102+/-4 \mathrm{~dB}$ & $49.5 \%$ & \\
\hline 5 & 110 & 754 & $107+/-3 \mathrm{~dB}$ & $9.5 \%$ & \\
\hline
\end{tabular}

Table 4 - Properties obtained from free vibration tests

\begin{tabular}{|l|c|c|}
\hline Specimens & $\mathrm{E}_{L}^{d}(\mathrm{GPa})$ & $\xi(\%)$ \\
\hline DRY & 33.9 & 0.87 \\
& \pm 0.6 & \pm 0.07 \\
\hline WVS & 27.2 & 1.33 \\
& \pm 0.9 & \pm 0.09 \\
\hline
\end{tabular}




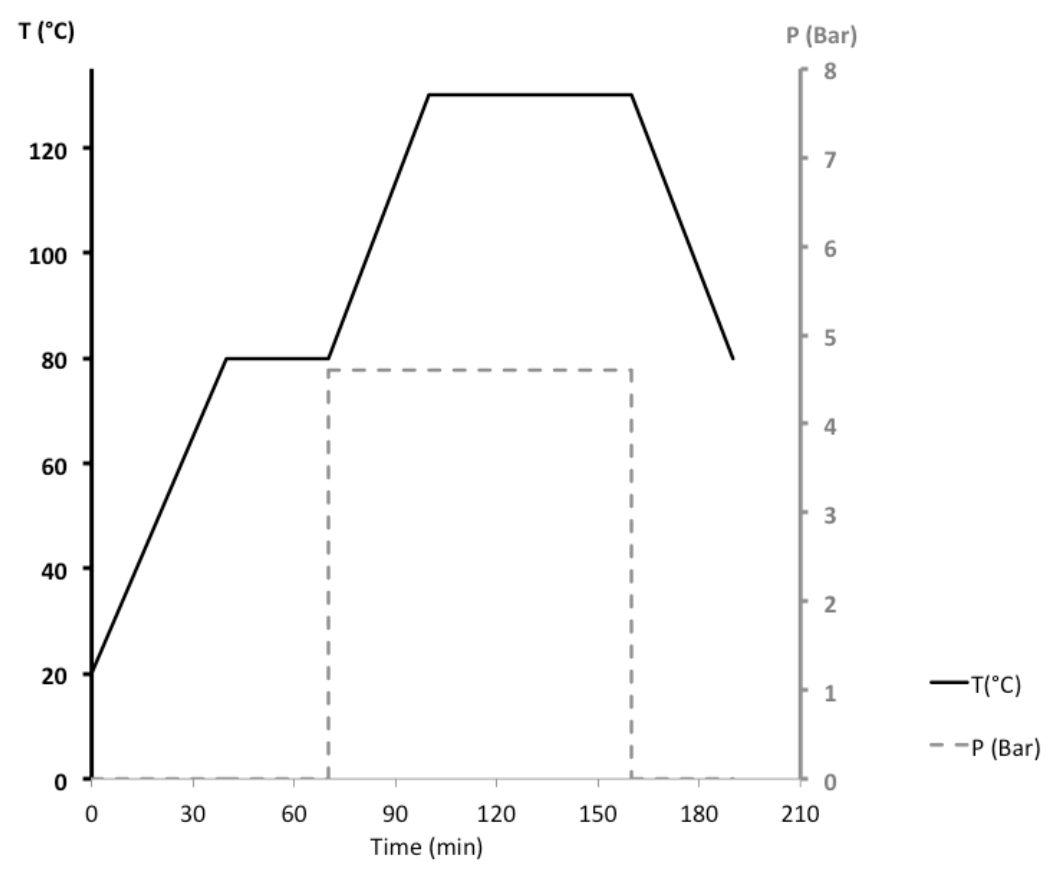

Figure 1: Pressure and temperature cycle used for curing materials

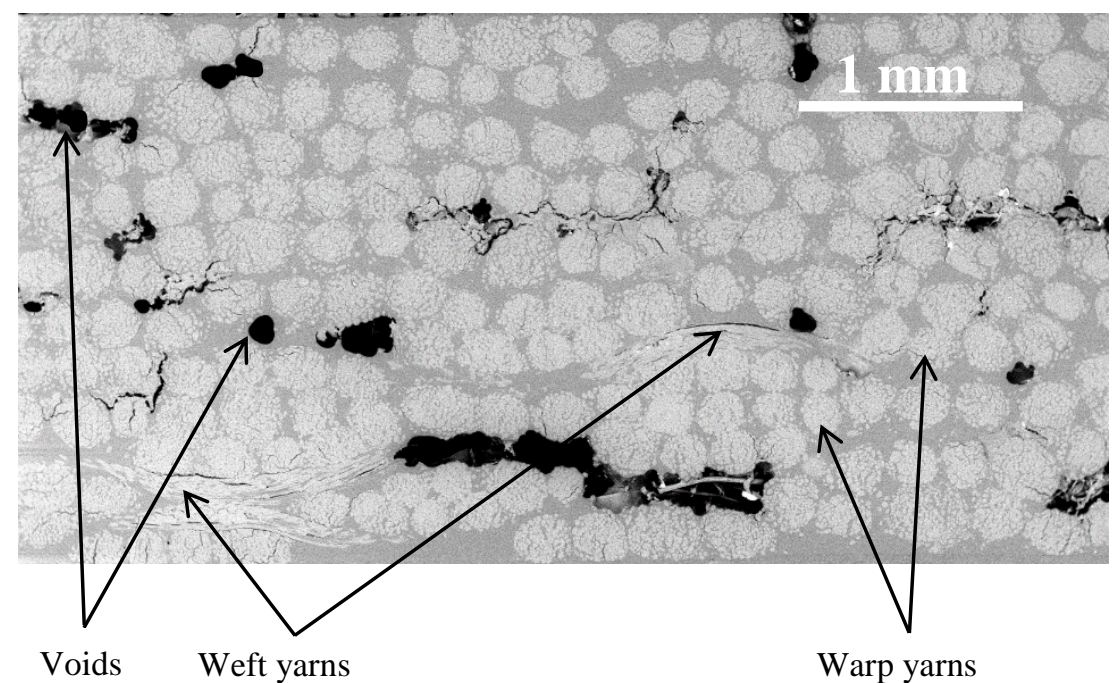

Figure 2: Scanning Electron Microscopy (SEM) cliché of the cross-section of the produced material 


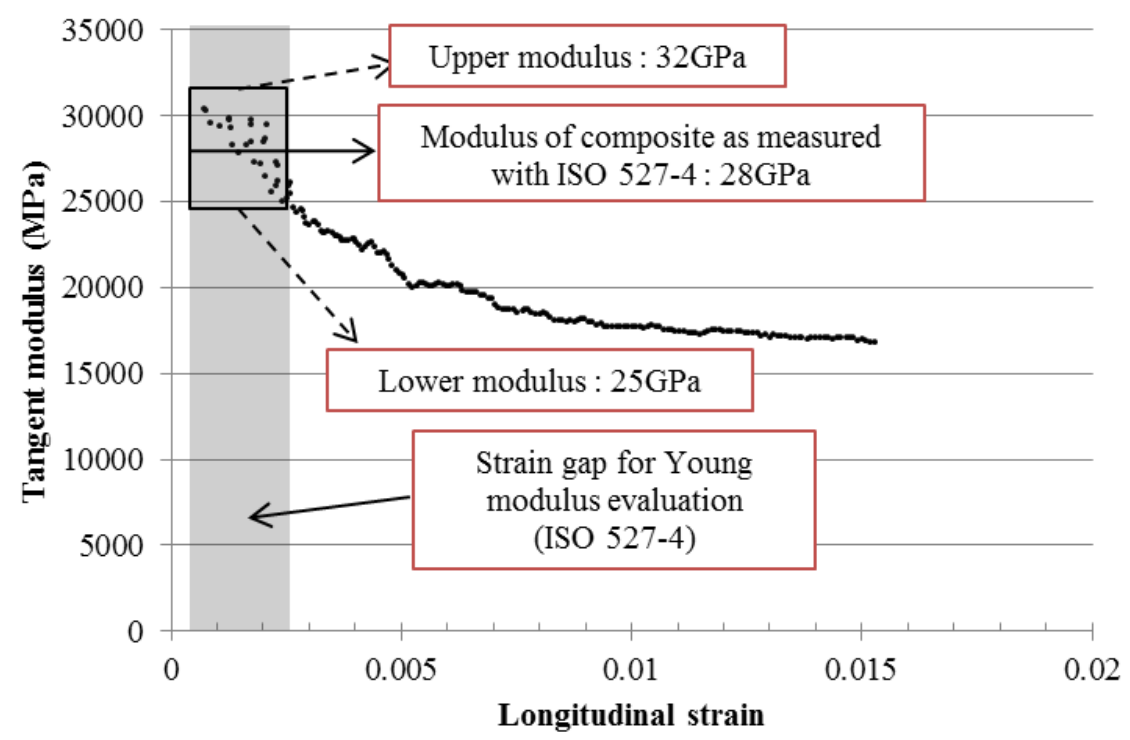

Figure 3: About the measurement of modulus in a plant fibre composite

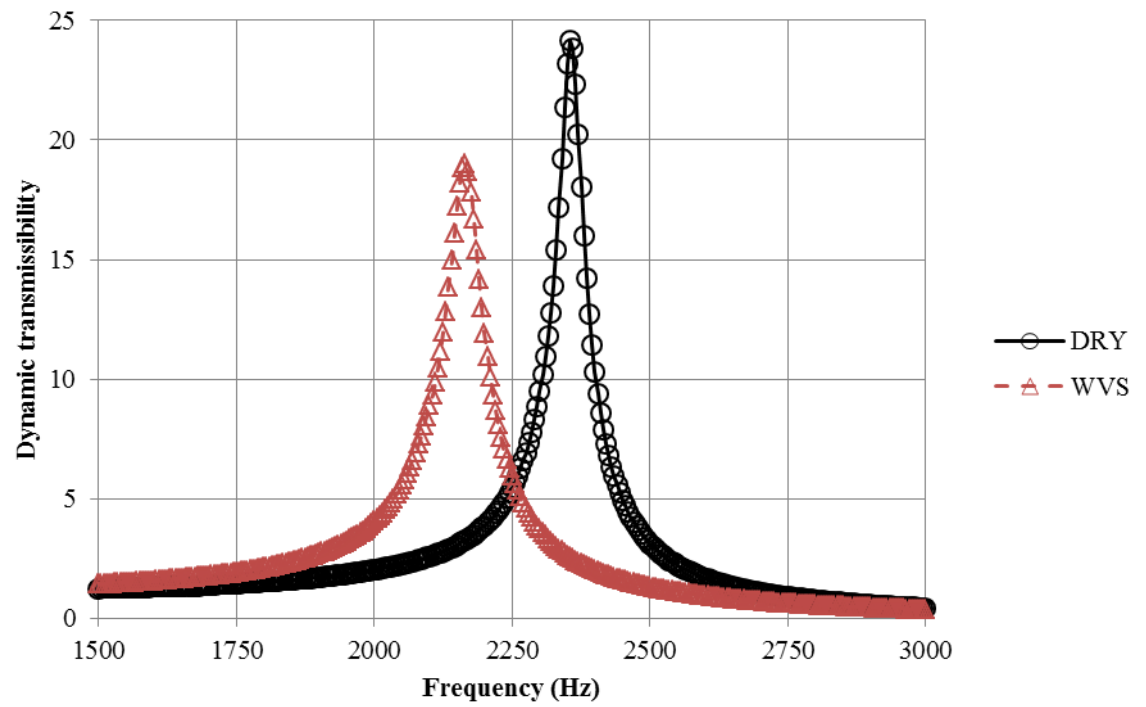

Figure 4: Typical impulse spectrum of the free vibration response of the composite samples 


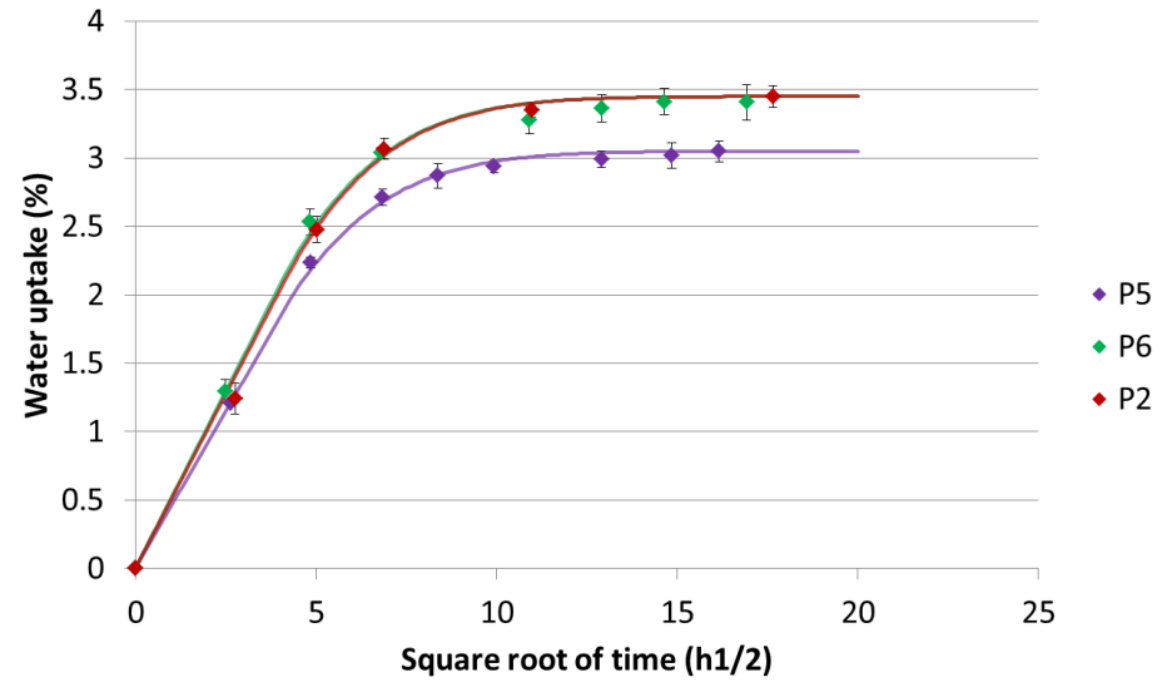

Figure 5 - Water uptake of composite samples and 1D-Fickian kinetic prediction (solid lines) when exposed to a hot humid environment $\left(7^{\circ} \mathrm{C} / 85 \% \mathrm{rh}\right)$ 
a.

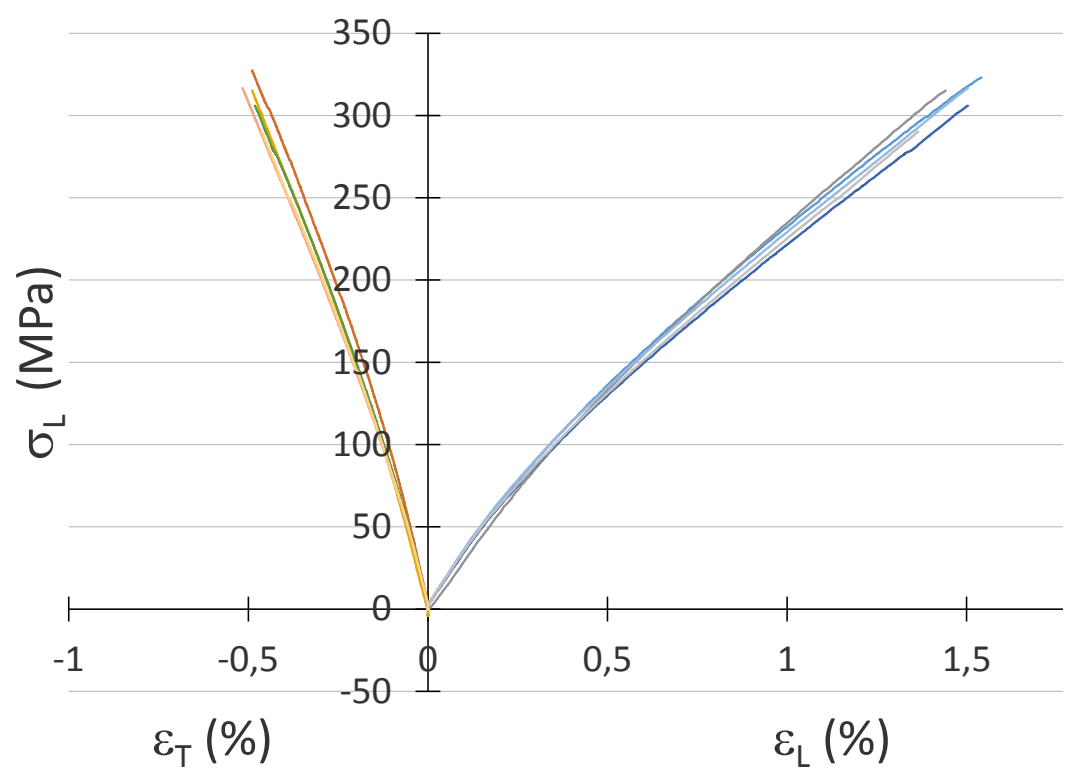

b.

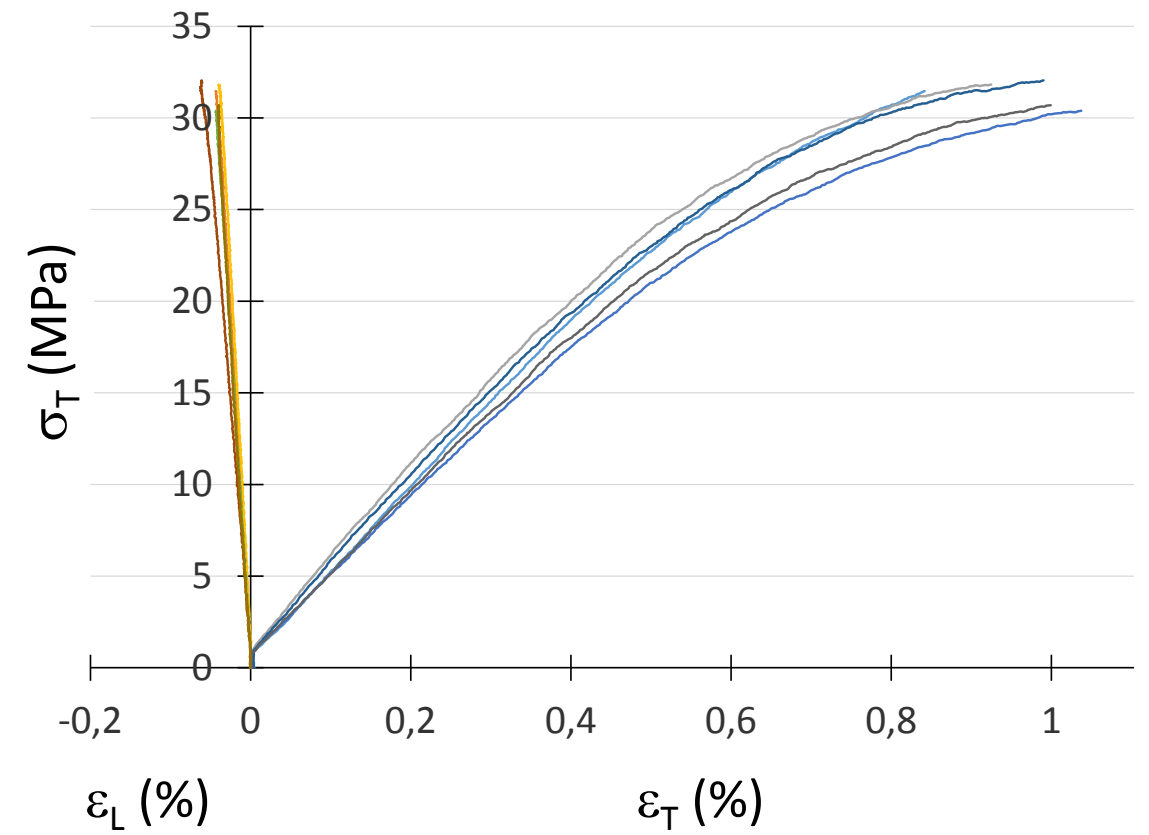

Figure 6 - Tensile stress-strains curves of $0^{\circ} \mathrm{UD}$ specimens (a) and $90^{\circ} \mathrm{UD}$ specimens (b) 


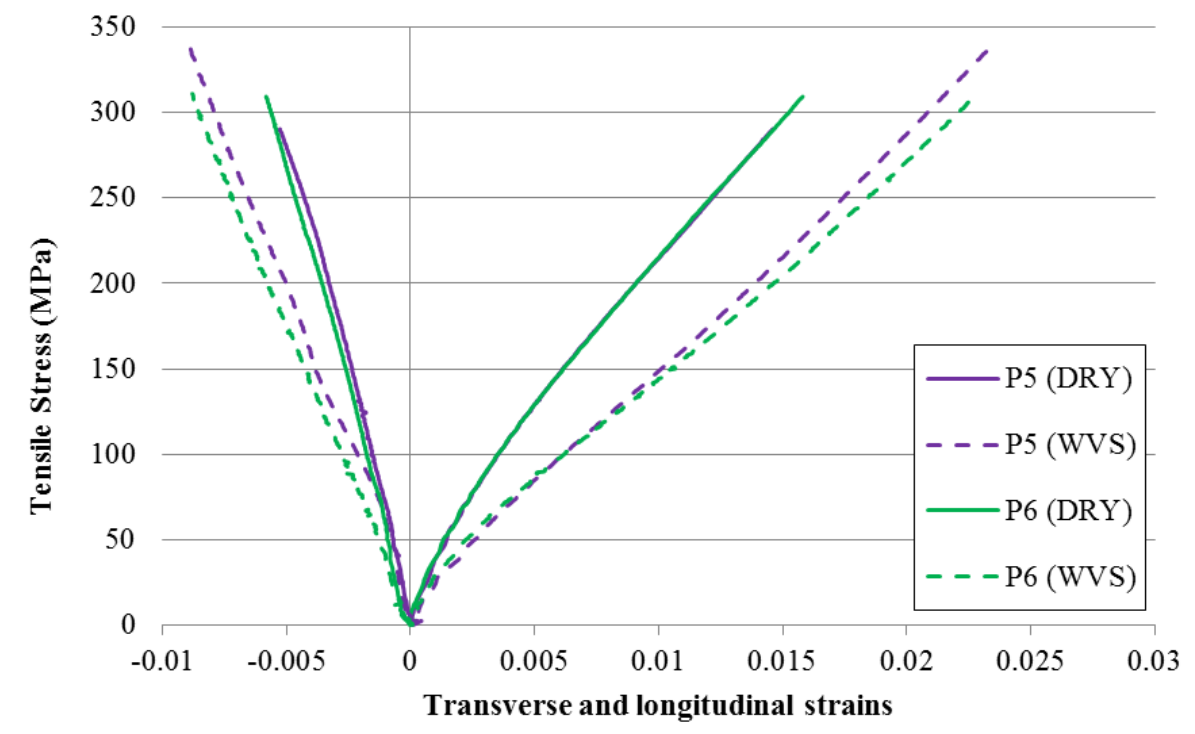

Figure 7: Tensile stress-strain curves for $0^{\circ} \mathrm{UD}$ specimens before and after aging

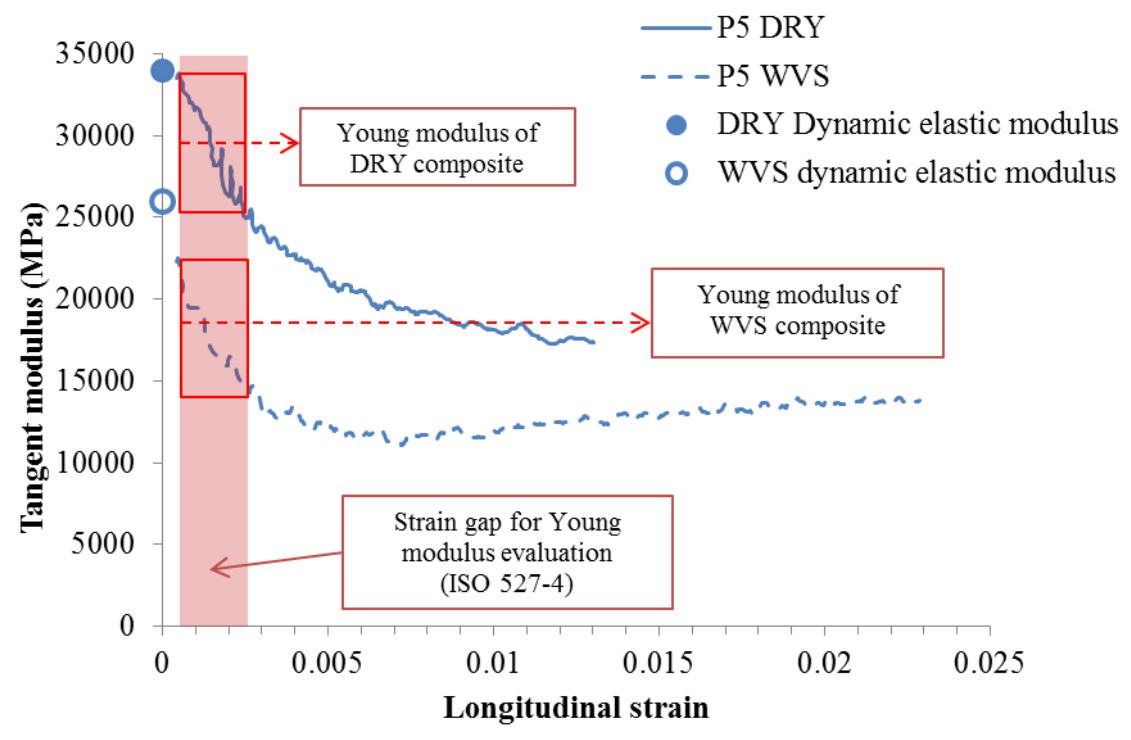

Figure 8: Evolution of tangent modulus with longitudinal strain for DRY and WVS samples measured during monotonic tensile test. Comparison with dynamic elastic modulus measured in free vibration. 


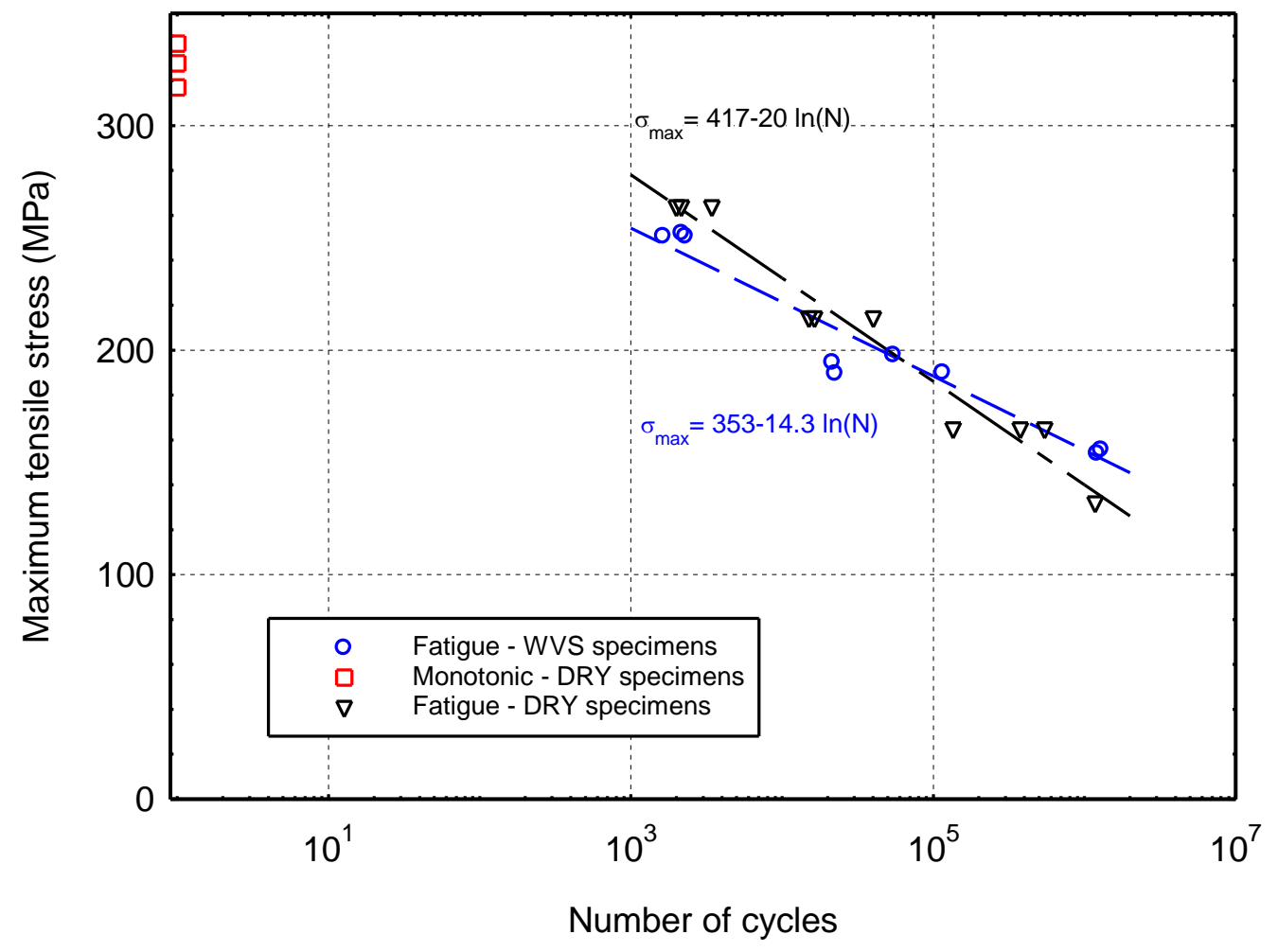

Figure 9: S-N curves of DRY and WVS specimens 
a.
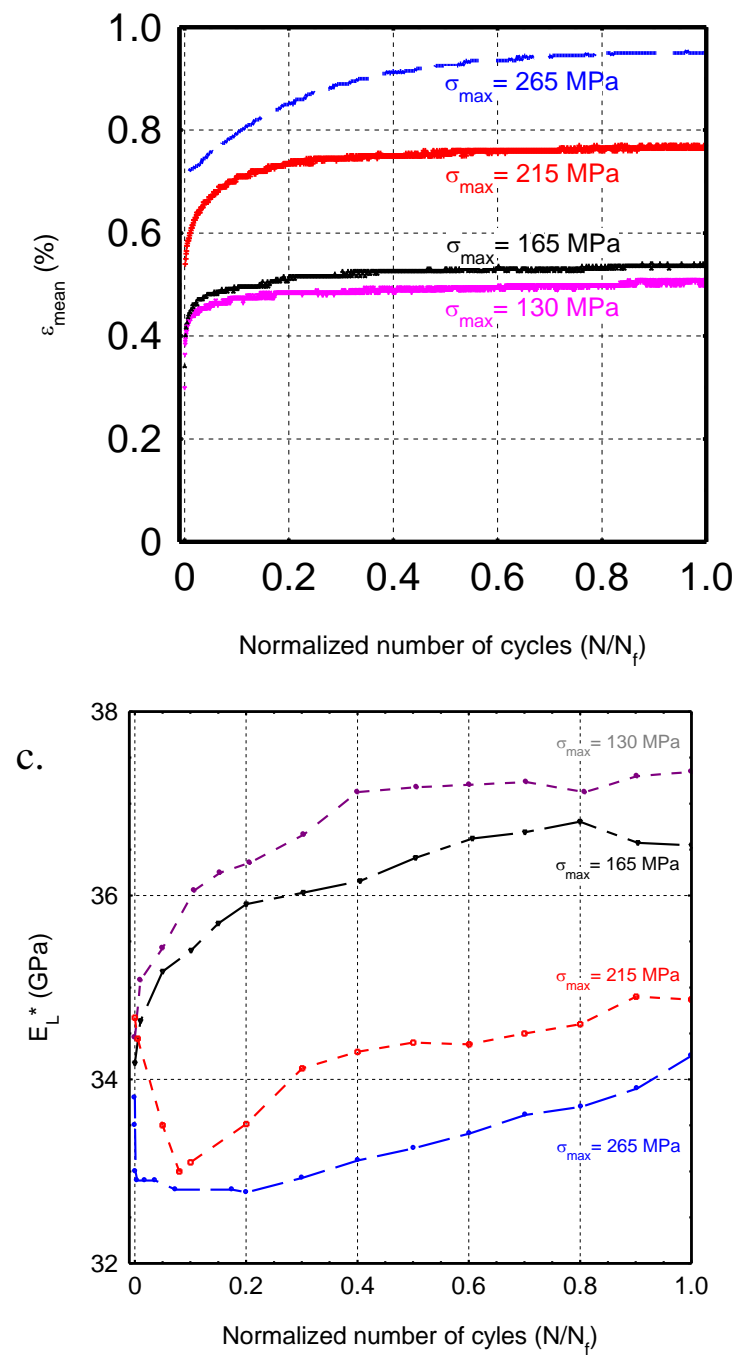

b.

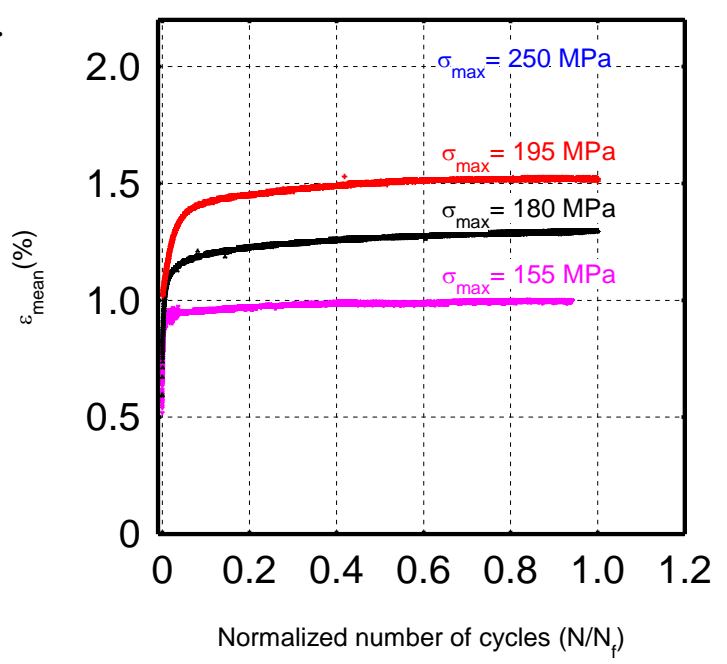

d.

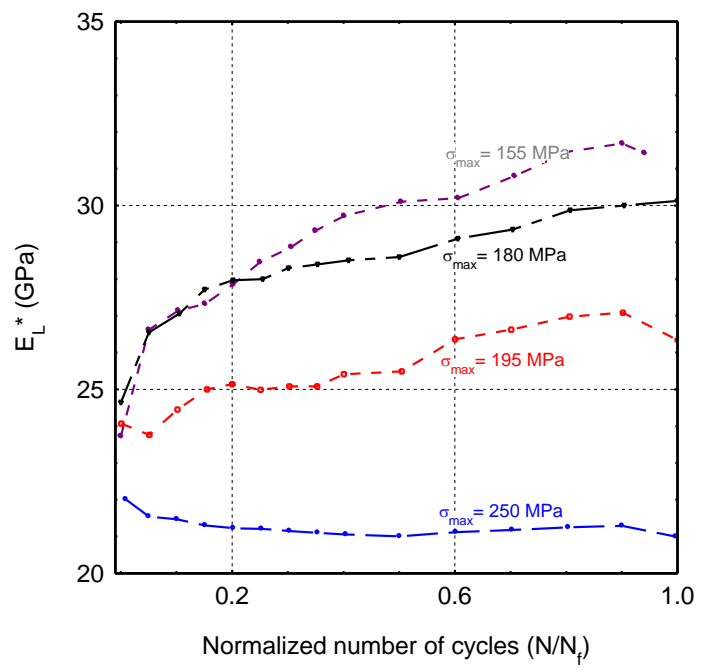

Figure 10: Typical curves of axial mean strain and dynamic elastic modulus recorded during fatigue tests as a function of normalized number of cycles, for different maximum stress levels, and for DRY (a. and c) and WVS specimens (b. and d.). 
a.

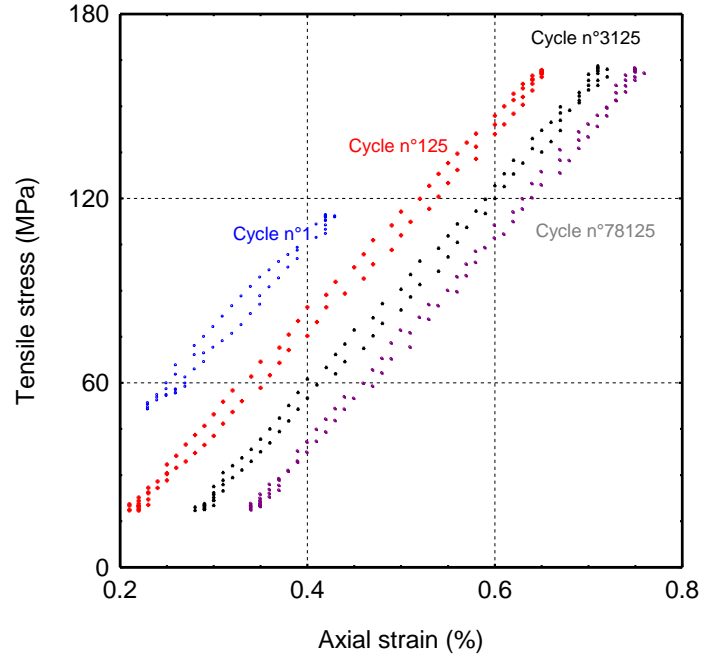

b.

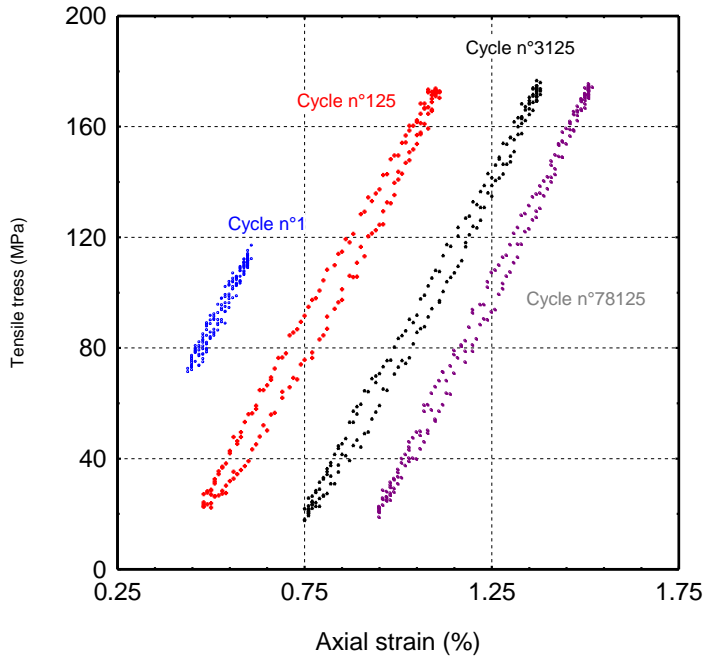

Figure 11: Hysteresis loops for different cycles $\left(n^{\circ} 1,125,3125\right.$ and 78 125) of: a. DRY (maximum dynamic stress $=50 \%$ of monotonic tensile strength) and $\mathrm{b}$. WVS specimens (maximum dynamic stress $=55 \%$ of monotonic tensile strength). 

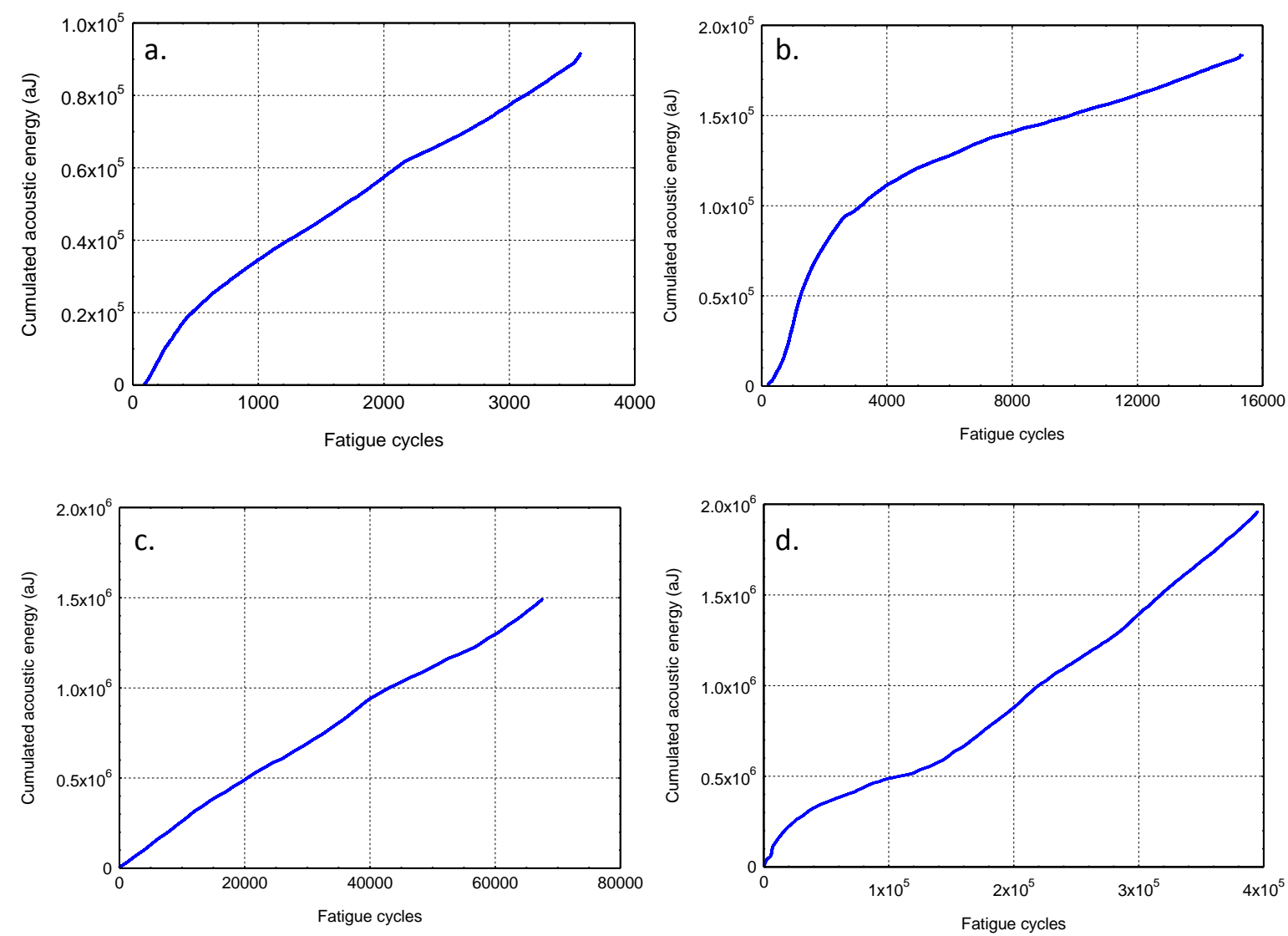

Figure 12: AE activity (i.e. cumulated number of $\mathrm{AE}$ hits) versus number of fatigue cycles. DRY specimens tested at a fatigue maximum stress equal to $80 \%$ (a.), $65 \%$ (b.), $50 \%$ (c.) and $40 \%$ (d.) of the monotonic tensile failure stress. 

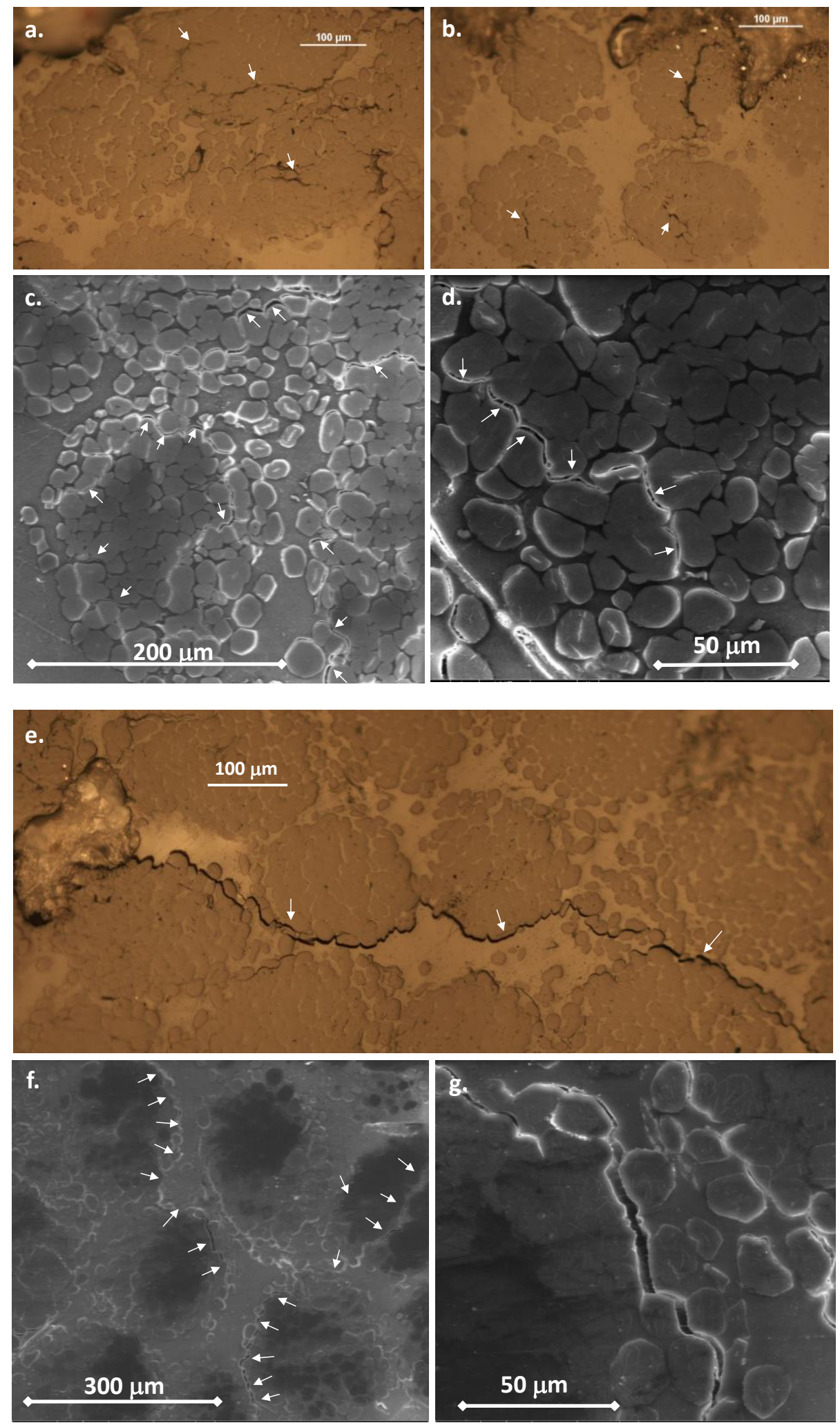

Figure 13: Micrographs of the cross section surface of laminates after fatigue failure for DRY specimen $(a, b, c, d)$ and WVS specimens $(e, f, g)$. 
a.
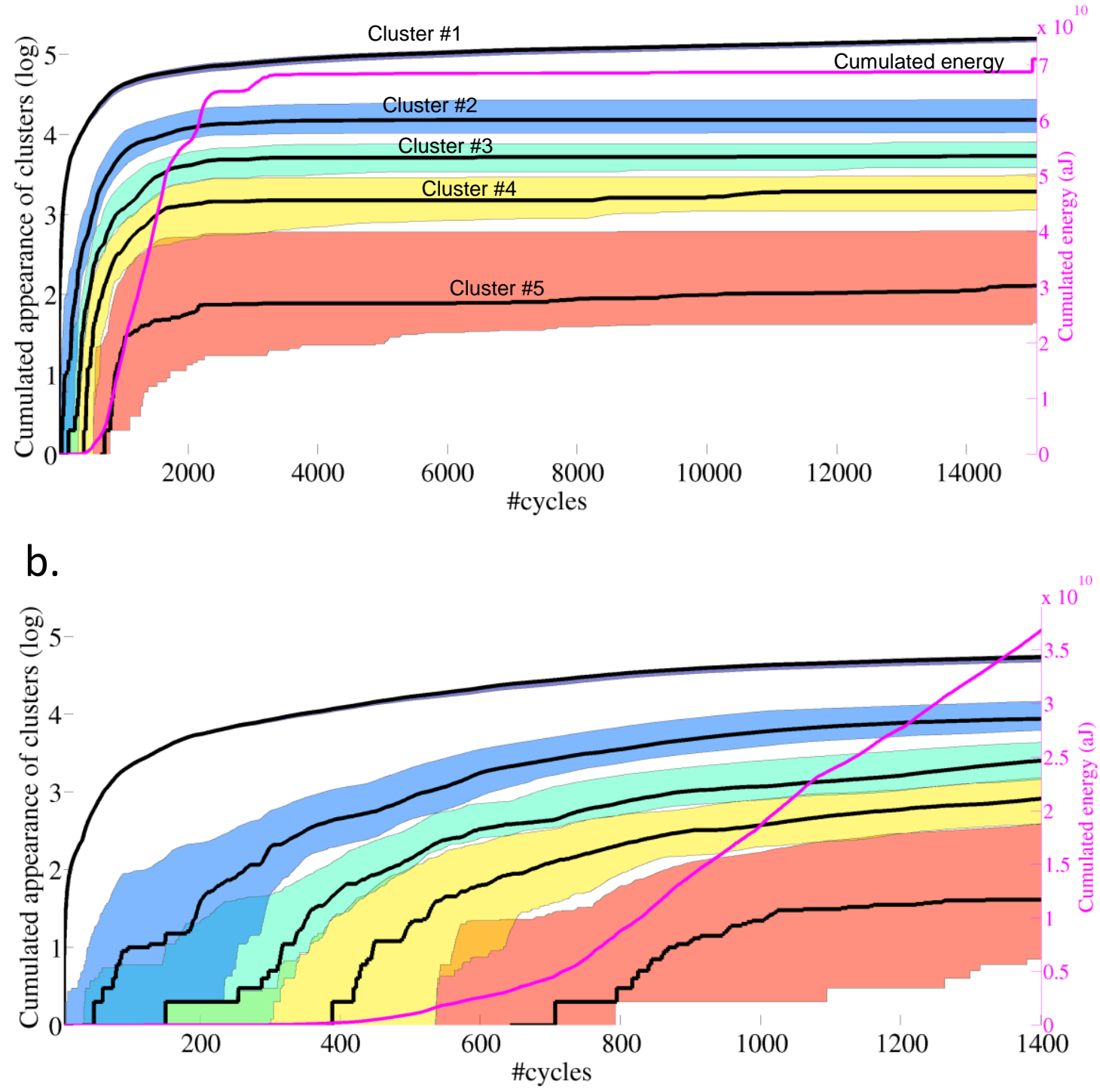

Figure 14: Activity in each cluster versus number of fatigue cycles for a DRY specimen tested at $65 \%$ of the monotonic tensile strength. The solid lines represent the best result of clustering fusion. The coloured envelopes describe the uncertainty resulting from clustering parametrization. a. Total fatigue lifetime. b. Zoom on the first 1400 cycles. 